\title{
In Cylinder Visualization of Stratified Combustion of E85 and Main Sources of Soot Formation
}

\author{
Lars Christian R. Johansen ${ }^{\mathrm{a}, *}$, Stina Hemdal ${ }^{\mathrm{a}}$ \\ ${ }^{a}$ Division of Combustion, Department of Applied Mechanics, Chalmers University of Technology, 41296 Gothenburg, Sweden
}

\begin{abstract}
The combustion process and soot formation in spark ignited spray guided stratified combustion of E85 was investigated in a single cylinder optical engine with direct injection of fuel using an outward opening piezo actuated injector. The effect of engine rotation frequency, fuel quantity, injection sequence and ignition timing was studied. Combustion, soot formation and soot oxidation was analysed using cylinder pressure measurements, images recorded using high speed video cameras, the flame emission spectrum and $\mathrm{OH}^{*}$ chemiluminescence and soot incandescence imaging. A maximum injection duration was found to exist for direct ignition of the fuel spray. Engine rotation frequency had little effect on the initial and maximum rate of combustion. The maximum rate of combustion decreased with increasing cycle fuel mass when a single injection was used. The rate of combustion and indicated mean effective pressure increased and the combustion variability decreased when the single injection was split into multiple injections in close succession to deliver the same total fuel mass and the last fuel spray was ignited. Ignition of the first fuel spray resulted in a more pronounced change. The absence of soot incandescence during the initial flame propagation suggested flame propagation in a partially mixed fuel and air mixture with stoichiometric to fuel lean regions. A single fuel injection resulted in piston pool fires due to fuel spray impingement on the piston and was the primary source of soot formation. The pool fires persisted until after conditions favourable to oxidation of the soot had ended. Soot formation in the gas phase occurred while favourable soot oxidation conditions existed and was efficiently oxidized. The magnitude of the piston pool fires was reduced using multiple injections. The reduction is attributed to a reduction of the fuel spray penetration length and a smaller effective injection orifice area, resulting in a shorter total duration of fuel spray impingement on the piston crown. Soot formation occurred primarily in the gas phase when the first of two fuel sprays was ignited and persisted due to the second fuel spray entering an existing flame leading to fuel rich combustion.
\end{abstract}

Keywords: stratified combustion, E85, piezo actuated outward opening pintle injector, optical engine, soot formation, multiple injections

\section{Introduction}

Spark ignited direct injection (SIDI) internal combustion engines provide several advantages in comparison to alternative designs with port fuel injection (PFI). Volumetric efficiency is increased due to the lack of fuel vapor in the intake port and vaporization of fuel in the cylinder lowers the cylinder gas temperature allowing the compression ratio to be increased [1]. The transient response is improved due to the lack of fuel film dynamics $[2,3]$.

In addition to the advantages of direct fuel injection in comparison to port fuel injection in stoichiometric homogeneous engine operation, direct injection also provides the means for stratified combustion which increases the maximum air to fuel equivalence ratio to the levels typical of unthrottled engine operation. Unthrottled engine operation reduces the pumping losses in the cylinder gas

\footnotetext{
* Corresponding author

Email address: larsch@chalmers.se (Lars Christian R. Johansen)
}

exchange process $[1,2]$ and the peak temperature of the cylinder gas mixture, reducing heat losses [4] and increasing expansion work [2]. Globally lean stratified combustion in a spark ignition engine requires a localised fuel and air mixture with an air to fuel ratio which can sustain a flame front and which also extends to the spark plug electrodes during the spark discharge. Fuel is injected late in the compression stroke thereby limiting the extent of fuel and air mixing in order to prevent the local air to fuel ratio increasing beyond the limit required for stable and complete combustion. In the spray guided concept the injector and spark plug are located in close proximity so the fuel spray from the injector passes the spark plug gap directly after the injector.

Due to the limited mixing of fuel and air the local stoichiometry immediately prior to ignition varies spatially and temporally in the cylinder with regions devoid of fuel, fuel lean and rich in fuel relative to the stoichiometric fuel to air ratio. Fuel rich conditions are known to be a prerequisite for the formation of soot in combustion [5]. Inho- 
mogeneously mixed fuel rich regions in diesel fuel sprays and diffusion combustion driven by injection of fuel into developed flames have been identified as a source of soot formation in diesel engines [6, Ch. 24]. Spray guided stratified combustion consists of both local premixed combustion and local diffusion combustion due to the stratified fuel distribution. Premixed and diffusion combustion in fuel rich regions created by late injection during the compression stroke for spray guided stratified combustion have been observed for gasoline [7, 8] and E85 [9] and both forms of combustion are expected to be a source of soot formation.

Liquid gasoline films on the surface of the piston created by the impingement of the fuel spray were observed in a wall guided engine with a multihole injector [10] and a spray guided engine with a swirl injector in near stoichiometric operation [11]. Delayin the start of injection nearer to TDC increased fuel film mass on the piston crown in an optical engine equipped with a centrally mounted swirl injector [11]. In this case, fuel films on the piston crown persisted for the duration of an engine cycle when fuel was injected in the second half of the compression stroke or in the first half of the intake stroke. In both studies combustion of the gasoline films on the piston crown resulted in diffusion flames referred to as pool fires.

Pool fires on the piston crown were confirmed as a source of soot formation in wall guided stratified combustion of gasoline using a multihole injector [10, 7] and in spray guided stratified combustion both with globally near stoichiometric conditions using a swirl injector [11] and with globally lean conditions using a multihole injector [12]. Fuel impingement on the piston crown and the resulting fuel films and pool fires could not be eliminated by phasing the start of injection during the end of the compression stroke in lean spray guided stratified combustion using a multihole injector [12]. Phasing of the start of injection did not affect particulate emissions although the IMEP increased with an earlier phasing [12]. The measured particulate emissions for two injection phasings late in the compression stroke resulted in approximately equal particulate emissions and pool fires were concluded to be the main source of soot formation in the given study. In contrast, the soot incandescence and particulate emissions measured in an optical engine [13] and particulate emissions in a single cylinder metal engine [8] increased as the start of injection was delayed in spray guided stratified operation with outward opening piezo actuated injectors. NOx emissions decreased as the start of injection was delayed towards TDC [8]. Hollow cone fuel spray impingement on the spark plug electrodes has also been observed to cause pool fires late in the combustion process [13]. The spark plug was positioned in close proximity to the piezo injector in order to ignite the fuel spray directly. An increase in the piston crown fuel film mass and soot formation from the resulting pool fires is a possible explanation if the fuel film created by the spray from a outward opening piezo injector increases with delayed injection analogous to the observations for a swirl injector hollow cone spray [11].

\subsection{Ethanol}

Ethanol is an alternative to gasoline in spark ignition engines with several advantages with respect to gasoline and gasoline surrogate fuel components. Ethanol is renewable $[14,15]$. While the lower enthalpy of combustion of ethanol is smaller in comparison with commercial gasoline, a greater mass of ethanol can combust with the same mass of air as a result of the lower stoichiometric air to fuel ratio of ethanol compared to normal alkanes due to the prescence of a hydroxyl group. As a result, the lower enthalpy of combustion per unit mass of a stoichiometric fuel air mixture for ethanol is 1.5 [\%] greater relative to isooctane. In addition, the cylinder gas temperature decrease due to vaporization of liquid fuel in the cylinder is greater for ethanol in comparison with gasoline due to an enthalpy of vaporization more than twice as large which allows the compression ratio to be increased.

Ethanol has a greater research octane number and motor octane number than commercial gasoline blends and blending of ethanol and commercial gasoline increases the fuel octane rating and allows a greater compression ratio [16]. The larger enthalpy of vaporization, viscosity and surface tension of ethanol likely yields greater droplet sizes than for primary reference fuels or gasoline as indicated by the hollow cone spray measurements of several fuels [17]. This behaviour has been confirmed for multihole sprays of E85 and gasoline at atmospheric conditions [18]. Due to the slower initial rate of vaporization of ethanol in comparison with gasoline and larger drop sizes, the liquid fraction at the same time during fuel injection will be larger which is undesirable with respect to soot formation.

Based on the laminar flame speed of ethanol/isooctane blends [19, 20], the laminar flame speed of E85 is expected to be close to that of ethanol and greater than isooctane and gasoline as a result. Under homogeneous conditions the rate of combustion is approximately equal for gasoline and E85 [18], while under lean stratified conditions the rate of combustion of E85 was observed to be larger compared to gasoline [21, 22, 23].

A reduction in NOx and soot with E85 relative to gasoline was observed in spray guided lean stratified combustion for both a multihole injector [9] and an outward opening piezo injector [8]. NOx was reduced further by delaying the start of injection towards TDC while soot was reduced slightly at a larger load and remained constant at a smaller load [23]. The lack of increased soot emissions as the start of injection was retarded nearer to TDC is in clear contrast to the increase in soot emissions observed for gasoline. Unburned hydrocarbon emissions were equal for E85 and gasoline with the piezo injector [8]. E85 was found to increase the maximum load at which lean stratified combustion could be used relative to gasoline as determined by a particulate emission limit in a single cylinder engine with an outward opening piezo actuated injector at 
the cost of increased specific fuel consumption corrected for lower heating value below 2000 [RPM] [22]. Above $2000[\mathrm{RPM}]$ and an IMEP of 6 [bar] the fuel consumption was lower in comparison with gasoline [22]. A reduction in $\mathrm{NOx}, \mathrm{CO}$, unburned hydrocarbon and soot emissions were observed over wide range of engine speeds and loads in the same study [22].

The literature findings demonstrate that in stratified combustion the use of E85 can reduce emissions compared to gasoline under the same operating conditions and further improvement is possible with later phasing of the start of injection with combustion. The reduction in emissions allow the lean stratified combustion to be used at larger engine loads given the equal emission limits for E85 and gasoline.

\subsection{Soot Formation and Oxidation}

Soot particles formed during combustion have a temperature equal to that of the surrounding gases and emit broadband thermal radiation in the visible and infrared spectrum [24]. A soot particle can be modelled as a blackbody with a wavelength dependent emissivity. Based on this model the spectral intensity of the luminescence emitted by a volume containing soot particles is a function of the temperature and wavelength according to Planck's law, the number of particles and the size distribution of the particles. The radiation emitted from a soot particle can be scattered and absorbed by other soot particles. Due to this the soot incandescence detected along an optical path through a region containing soot is also a function of the soot density and path length. The effect of the soot density and optical path length can be roughly quantified in terms of a $K L$ factor, where $K$ is an absorption coefficient proportional to the number density of soot particles and $L$ is the path length of the radiation [24].

The mechanism of soot oxidation is the subject of ongoing research and has been shown to involve $\mathrm{O}_{2}$ and the oxygen containing $\mathrm{O}$ and $\mathrm{OH}$ radicals amongst other species $[5,6]$. A studyfound that soot from premixed ethylene and acetylene flames was reduced by an order of magnitude when the oxidizer was changed from $\mathrm{N}_{2} \mathrm{O}$ to $\mathrm{O}_{2}$ while maintaining the same stoichiometry and flame temperature [25]. Equal concentrations of the presumed aggregate precursor species were measured in both cases and the reduction in soot was attributed to the greater abundance of $\mathrm{OH}$ radicals from the $\mathrm{O}_{2}$ and oxidation of the soot aggregates by $\mathrm{OH}$. The formation, structure and oxidation of soot in a propane concentric coflow diffusion flame at atmospheric pressure was investigated in a study by [26]. The soot size measured by Raman scattering of sampled soot and the soot volume fraction determined with laser induced incandescence decreased as the intensity of the laser induced fluorescence of $\mathrm{OH}$ increased suggesting soot oxidation by $\mathrm{OH}$. Under diesel engine conditions the oxidation of soot in two diesel surrogate fuels was found in both cases to coincide with a decrease in $\mathrm{CO}$ from peak concentrations through oxidation by $\mathrm{OH}$ radicals by [27].
It was argued that the reduction in $\mathrm{CO}$ left more $\mathrm{OH}$ radicals available for the oxidation of soot through a parallel reaction with a lower kinetic rate to that involving $\mathrm{OH}$ and CO.

The radical $\mathrm{OH}$ is created during oxidation of hydrocarbons as a product of chain branching and propagating reactions and is a reactant in exothermic chain propagating reactions [28, Ch. 3]. In reaction mechanism models of ethanol [29] and E85 [30] oxidation, $\mathrm{OH}$ is involved in the initial decomposition of ethanol. Based on these results the prescence of $\mathrm{OH}$ is an indication of oxidation of E85 and conditions conducive to the oxidation of soot. $\mathrm{OH}$ in the first higher electronic state, denoted $\mathrm{OH}^{*}$, emits radiation centered in a narrow band around 306 [nm] when relaxing to the ground electronic state at the temperatures present in flames $[31,32]$. $\mathrm{OH}^{*}$ can occur as the product of chemical reactions [31] and the emitted luminescence is referred to as chemiluminescence. In hydrocarbon flames the reaction in Eq. 1 is a source of $\mathrm{OH}^{*}[33,34]$.

$$
\mathrm{CH}+\mathrm{O}_{2} \longrightarrow \mathrm{OH}^{*}+\mathrm{CO}
$$

The $\mathrm{OH}^{*}$ chemiluminescence intensity is dependent on the local temperature and chemical composition [35]. Soot particles attenuate $\mathrm{OH}^{*}$ chemiluminescence in the same manner as with soot incandescence [13] and due to this the $\mathrm{OH}^{*}$ chemiluminescence intensity decreases as the line of sight soot density increases. Spatially and temporally resolved $\mathrm{OH}^{*}$ chemiluminescence and soot incandescence was measured by [7] using two bandpass filtered cameras and used to study soot formation, soot density and soot temperature using two colour pyrometry in wall guided stratified combustion of gasoline using a multihole injector in a single cylinder optical engine. Crank angle averaged and spatially resolved $\mathrm{OH}^{*}$ and soot incandescence was used by [13] to study soot formation and oxidation in spray guided combustion of gasoline using a piezo outward opening injector.

\subsection{Study}

In this study the combustion process, sources of soot formation and soot oxidation in E85 globally lean stratified combustion was investigated using high speed imaging of natural luminosity and spatially and temporally resolved $\mathrm{OH}^{*}$ chemiluminescence and soot incandescence. The same engine and injector type as used in the study by [13] was used in this study. The effect of the engine rotational frequency, denoted $\omega[\mathrm{RPM}]$, engine load, injection procedure and ignition timing on combustion and soot formation and oxidation was investigated. Unthrottled engine operation was studied and the fuel pressure was constant. Two engine loads were investigated. The engine load was defined in terms of the injected fuel mass per cycle, denoted $m_{\mathrm{f}}[\mathrm{kg}]$, instead of in terms of engine work or indicated mean effective pressure (IMEP). The injected fuel mass per cycle can be controlled more accurately than the engine work and is dependent on fewer uncontrollable 
factors such as ambient temperature, pressure and humidity. The two values for the injected fuel mass per cycle defining each of the two engine loads were determined as those required for an IMEP of 3.6 [bar] and 5.8 [bar] respectively with a single fuel injection at $1500[\mathrm{RPM}]$ and was found to be 18 and 26 [mg] respectively. The procedure that was used to determine the fuel mass values is detailed in Section 3. The measured lambda for the two engine loads were 2.6 and 1.7 respectively indicating that combustion with both fuel mass quantities was globally lean.

Multiple injections of gasoline were found to increase the rate of combustion, the IMEP and the combustion stability for spray guided stratified combustion of gasoline $[22,36]$ and E85 [22]. Based on these results, the effect of multiple injections on soot formation was selected for investigation in this study. The injection procedure was varied through the number of injections, denoted $n_{\text {inj }}[-]$ and the delay between injections, denoted $d_{\text {inj }}[\mu \mathrm{s}]$. The duration of individual injections was held constant when multiple injections were used. The beginning of the spark was set to coincide with the end of the fuel injection for all experiments conducted except for one case. One experiment was conducted with the spark set to occur at the end of the first of two fuel injections in a cycle.

\section{Experiment Setup}

An AVL 5411.018 single cylinder optical engine with a pent roof cylinder head was used in this study. A piezo actuated, outward opening, pintle needle fuel injector and a triple electrode spark plug were mounted in the centre of the combustion chamber roof between the intake valves and the exhaust valves. A diagram of the engine is shown in Figure 1.

A quartz window was mounted in each of the two pent roof gables in the cylinder head. The head was mounted on top of a quartz cylinder liner with a height of 25 [mm] with a metal ring join between the two. The vertical distance from the injector tip to the piston surface at top dead center was $12[\mathrm{~mm}]$. The distance from the injector tip to the spark gap was $8[\mathrm{~mm}]$. The piston was visible through the quartz cylinder liner between -60 [CAD] and 60 [CAD] after top dead center (aTDC) firing. Background illumination for the purposes of visualizing the liquid fuel and piston motion viewed through the optical cylinder liner was provided by an LED with a dispersing lens mounted.

An elongated piston with a flat quartz window crown was used in the engine. The quartz piston crown provided a view of the combustion chamber along the cylinder axis by means of a mirror positioned below the piston in a Bowditch configuration [37]. The mirror was inclined at an angle of $45\left[^{\circ}\right]$ with respect to the cylinder axis and was visible through a slot in the elongated piston skirt as illustrated in the diagram on the left in Figure 1.

Figure 2 shows the combustion chamber and cylinder head as viewed from below through the quartz piston

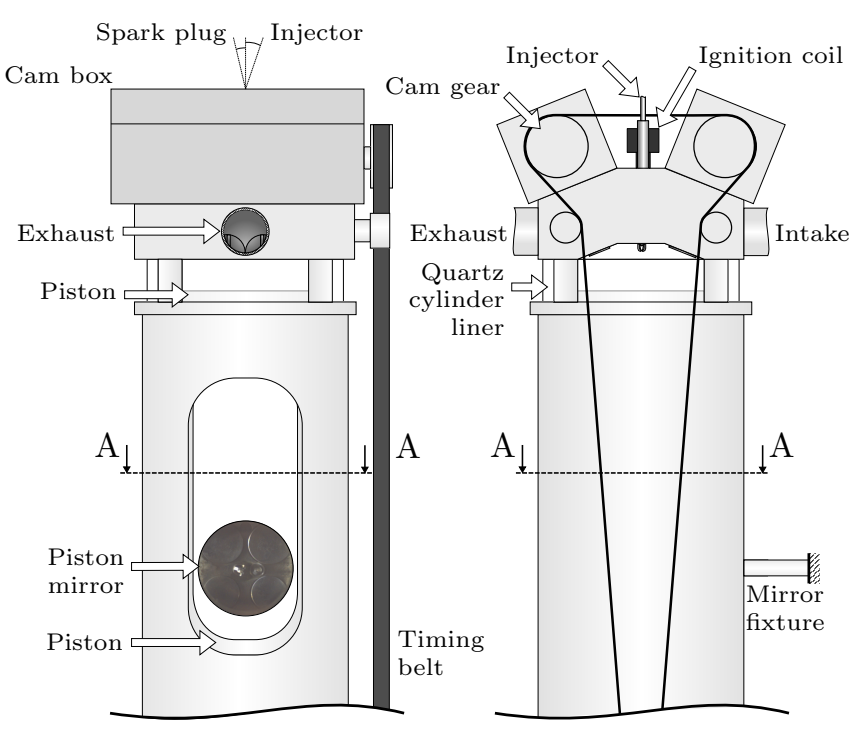

Figure 1: Diagram of the optical single cylinder engine. The piston mirror camera and cylinder liner camera faced the engine sides shown to the left and right respectively. The section corresponding to the $\mathrm{A}-\mathrm{A}$ cut plane is shown in Figure 4 and Figure 3.

crown using the piston mirror. The pent roof quartz windows are located on the left and right hand sides of the combustion chamber image in Figure 2. The position of the injector tip and the spark plug tip is shown in Figure 2. The injector was inclined $20\left[^{\circ}\right]$ clockwise from the cylinder axis in the plane of the diagram on the left in Figure 1 and the spark plug was inclined $10\left[^{\circ}\right]$ counter clockwise. The inclinations are indicated in Figure 1. Fixed engine parameters are given in Table 1.

\begin{tabular}{lr}
\hline Bore & $83.06[\mathrm{~mm}]$ \\
Stroke & $90[\mathrm{~mm}]$ \\
Connecting rod length & $139.5[\mathrm{~mm}]$ \\
Compression ratio & $10.1[-]$ \\
Displacement volume & $0.488 \cdot 10^{-3}\left[\mathrm{~m}^{3}\right]$ \\
Clearance volume & $0.535 \cdot 10^{-4}\left[\mathrm{~m}^{3}\right]$ \\
Number of intake valves & 2 \\
Intake valve diameter & $33[\mathrm{~mm}]$ \\
IVO/IVC (aTDC firing) & $340 /-120[\mathrm{CAD}]$ \\
Number of exhaust valves & 28 \\
Exhaust valve diameter & $28[\mathrm{~mm}]$ \\
EVO/EVC (aTDC firing) & No swirl and low tumble \\
Swirl and tumble & piezo actuated \\
Injector & outward opening pintle \\
& spray guided \\
Stratified operation & $205[\mathrm{bar}]$ \\
Fuel pressure &
\end{tabular}

Table 1: Single cylinder optical engine specifications.

The engine was operated at a fixed rotational speed using a dynamometer connected to the crankshaft of the engine. An AVL 4210 instrument controller was used to generate trigger pulses beginning or ending at a specified crank angle with a specified crank angle or time duration. All experiments were conducted with a constant ignition 


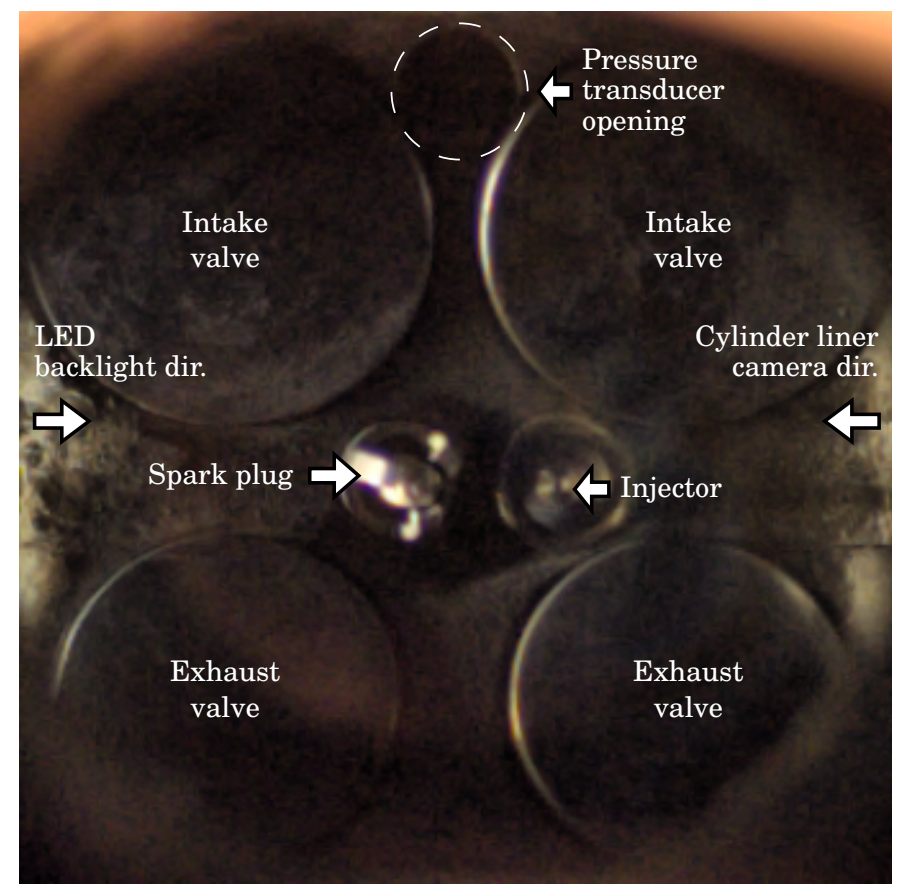

Figure 2: The combustion chamber viewed from below through the quartz piston crown.

coil charging duration with the aim being a constant spark energy. The trailing edge of the ignition coil trigger initiated the spark and the spark timing was controlled by shifting this edge. The start of spark (SOS) timings given in this paper are the ignition coil trigger trailing edge timings. The start of injection and injection durations and delay between injections were controlled in a similar manner with trigger pulses to the injector driver unit. The AVL 4210 was used to trigger a digital delay generator which in turn generated trigger pulses to the injector driver. The start of injection was initiated by the leading rising edge of the first trigger pulse to the injector driver. The start of injection (SOI) timings given in this paper correspond

\begin{tabular}{llr}
\hline Property & Method & Value \\
\hline Density $(288.15[\mathrm{~K}])$ & ISO 12185 & $787.3\left[\mathrm{~kg} / \mathrm{m}^{3}\right]$ \\
Vapour pressure & EN 13016-1 & $36.6[\mathrm{kPa}]$ \\
Water & EN ISO 12937 & $0.2[\% \mathrm{w}]$. \\
& & $0.16[\% \mathrm{vol}]$. \\
Ethanol & SGS-S-01-2006 & $87.1[\% \mathrm{w}]$. \\
& & $86.4[\% \mathrm{vol}]$. \\
Methanol & EN 13132 & $<0.2[\% \mathrm{w}]$. \\
& & $<0.2[\% \mathrm{vol}]$. \\
Isobutanol & EN 13132 & $0.4[\% \mathrm{w}]$. \\
& & $0.39[\% \mathrm{vol}]$. \\
MTBE & EN 13132 & $2.7[\% \mathrm{w}]$. \\
& & $2.9[\% \mathrm{vol}]$. \\
Gasoline & Calculated & $13.6[\% \mathrm{vol}]$. \\
Final boiling point & SS-EN ISO 3405 & $353.95[\mathrm{~K}]$ \\
Lower heating value & & $29.2[\mathrm{MJ} / \mathrm{kg}]$ \\
\hline
\end{tabular}

Table 2: Properties and composition of the E85 fuel used in the experiments. The calculated gasoline fraction includes gasoline, MTBE and isobutanol. to the timing of the leading edge of the injector driver trigger pulse. The injection duration $t_{\text {inj }}$ was defined as the duration between the rising leading edge and falling trailing edge of the injection trigger signal. The delay duration $d_{\text {inj }}$ between injections was defined as the duration between the falling trailing edge of one injection and the rising leading edge of the next injection.

A commercial certified test fuel consisting of 86.4 [\%.vol] ethanol and 13.6 [\%.vol] gasoline by volume was used. Fuel properties and composition are given in Table 2. The fuel was supplied to the injector at a pressure of 205 [bar] by a radial piston fuel pump which in turn was supplied by a low pressure pump at 4 [bar]. The fuel mass flow was measured using a coriolis mass flow meter between the fuel tank and the low pressure pump. An air to fuel ratio sensor was mounted in the exhaust pipe.

The engine was fired continuously for a duration of 100 cycles when measurements of combustion phenomena were performed and otherwise motored. The engine could not be operated continously as this would cause the quartz components of the engine to fracture and fail. As a result the engine component temperatures increased while the engine was fired. A skip fire strategy can be used to establish quasi steady engine component temperatures that are lower than the quasi steady state temperatures that occur with continous engine firing [9]. Skip firing of the engine was not feasible for the experiments detailed in this paper due to the accumulation of soot on the quartz piston crown prior to achieving a quasi steady engine temperature. The accumulation of soot on the piston crown is discussed in greater detail in Section 4.

The measurements performed during the engine experiments and the apparatus arrangement used are described in the following sections.

\subsection{Cylinder Pressure}

A differential piezo pressure sensor was used to measure the change in cylinder pressure. The sensor was mounted horizontally on the side of the intake valves. The opening to the pressure sensor is indicated in Figure 2. The cylinder pressure was measured for a duration of 100 cycles for each experiment. The same measurement duration was used for measuring the motored engine cylinder pressure. In the crank angle range -45 to 45 [CAD] the pressure was recorded at intervals of 0.1 [CAD] and otherwise at intervals of 1 [CAD]. The indicated mean effective pressure (IMEP) and heat release were calculated from the pressure measurements. At $1000[\mathrm{RPM}]$ the intake manifold pressure was $97.6[\mathrm{kPa}]$ and at $1500[\mathrm{RPM}]$ the intake manifold pressure was $95.9[\mathrm{kPa}]$

\subsection{Imaging}

Images of the injection of fuel, spark ignition and flame development were recorded using video cameras. Images were recorded from below the combustion chamber through the quartz piston crown by means of the piston mirror 
and from the side of the combustion chamber through the quartz cylinder liner. These images are designated as the piston images and liner images respectively. A colour Vision Research Phantom Miro M310 camera with a $50 \mathrm{~mm}$ lens set to f/1.4 and a monochrome Vision Research v1210 camera with a $50 \mathrm{~mm}$ lens set to $\mathrm{f} / 22$ were used to capture images from the two perspectives respectively.

The size of the images captured was $320 \times 320$ [pixel] for the piston images and $384 \times 384$ [pixel] for the liner images with a scale of $0.3[\mathrm{~mm} /$ pixel $]$ for both sets.

Experiments with an engine rotational frequency of $1500[\mathrm{RPM}]$ images were recorded at a frequency of $20[\mathrm{kHz}]$ with an exposure time of $44.34[\mu \mathrm{s}]$. At 1500 [RPM] the frame frequency corresponds to an crank angle interval of 0.45 [CAD]. The exposure time corresponds to a crank angle duration of 0.4 [CAD].

Images were captured beginning $2[\mathrm{CAD}]$ prior to the start of injection and for a duration of 100 [CAD]. The number of cycles recorded in this crank angle interval was 50. The frame rate was the same for both cameras and the frames were synchronized. The cameras were not synchronized with the beginning of the recording crank angle window. The start of the memory gating signal to the cameras could occur at any point during the exposure of the first image in every cycle and the exact start of exposure for that first image in a cycle is therefore uncertain. The crank angle calculated for each image has a maximum error of +0.4 [CAD] relative to the true crank angle as a result.

The LED backlight was on prior to the start of the spark in order for the liquid fuel to be visible in both image sets and for the piston to be visible in the liner images.

\subsection{Emission Spectrum}

The spectrum of the emitted electromagnetic radiation from the spark and combustion was measured to identify chemical species present during the ignition and subsequent combustion of the fuel and air mixture, and to select appropriate filters for the $\mathrm{OH}^{*}$ chemiluminescence and soot incandescence measurements. The luminescence and incandescence passing through the quartz piston crown and reflected by the piston mirror were analyzed. The radiation measured is the line of sight sum along the cylinder axis. The apparatus arrangement used for the spectrum measurements is illustrated in Figure 3.

A plate beamsplitter with $70 \%$ reflection and $30 \%$ transmission was used to direct luminescence towards the spectrometer arrangement. The luminescence was focused by a lens on to a fixed vertical slit with a width of 0.25 [mm]. The radiation passing through the slit was directed on to a reflecting diffraction grating and the diffracted radiation was reflected on to a Hamamatsu C9548-04 image intensifier. The image intensifier was used as a sensor for incident radiation in the wavelength interval $185[\mathrm{~nm}]$ to 900 [nm]. The incident electromagnetic radiation signal was amplified and converted to broad spectrum electromagnetic radiation with a peak at 530 [nm]. The output of

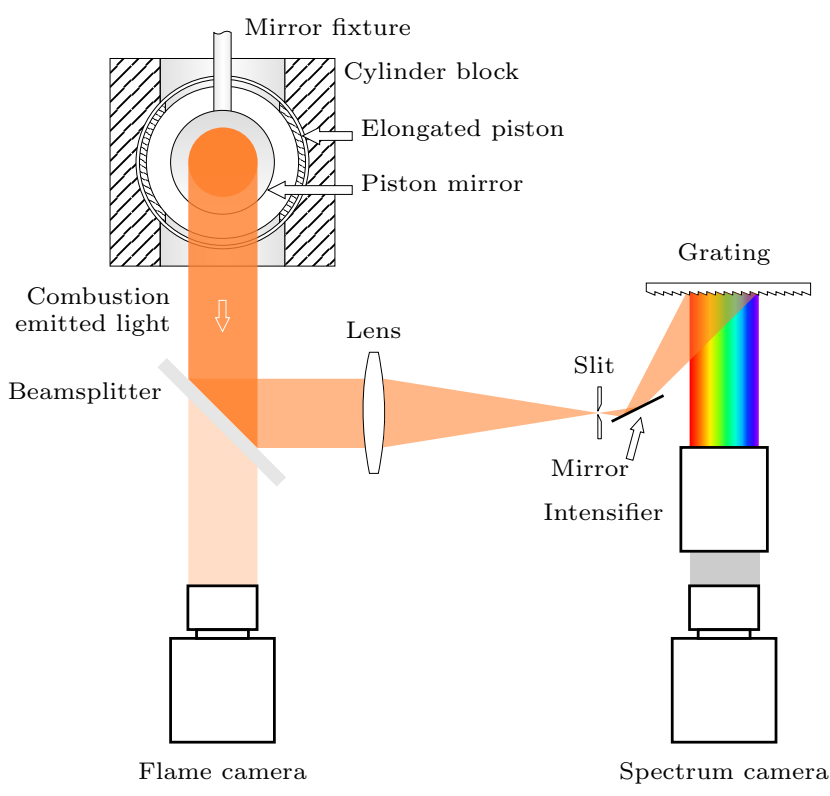

Figure 3: Diagram of the optics arrangement used to measure the spectrum of the emitted radiation. The arrangement is viewed from above. The location of the cut plane for the engine section shown is indicated by the $\mathrm{A}-\mathrm{A}$ cut plane in Figure 1.

the intensifier was recorded using a Vision Research v7.1 video camera, designated as the spectrum camera. The camera was operated with a frame frequency of $9009[\mathrm{~Hz}]$ at 1500 [RPM]. The frame frequency corresponds to an crank angle interval of 1 [CAD] between recorded images. The exposure time was $100[\mu \mathrm{s}]$ with a corresponding crank angle duration 0.9 [CAD].

The vertical slit limited the area of the combustion chamber measured by the spectrometer to a rectangle delimited by the bounding box shown in Figure 14 . The spectrum measurements were spatially resolved along the length of rectangle with a scale of $0.3[\mathrm{~mm} /$ pixel $]$.

The spectrometer arrangement was calibrated with a Hg lamp. A wavelength interval of 193 [nm] to 847 [nm] was measured with a wavelength scale of $0.8[\mathrm{~nm} /$ pixel].

The luminescence transmitted by the beamsplitter was used to record images of the spark and combustion using a Vision Research Miro M310 frame synchronous with the spectrum camera and designated as the flame camera. The exposure time was equal to the spectrum image exposure times.

\section{4. $\mathrm{OH}^{*}$ Chemiluminescence and Soot Incandescence}

The chemiluminescence emitted from $\mathrm{OH}^{*}$ and soot incandescence was measured simultaneously with the arrangement illustrated in Figure 4. The measured radiation at each pixel is the line of sight sum along the cylinder axis.

A dichroic mirror with a wavelength center at 308 [nm] and a full width at half maximum (FWHM) of 50 [nm] reflected the $\mathrm{OH}^{*}$ chemiluminescence towards a bandpass filter with FWHM of 10 [nm]. A Hamamatsu C9548-04 


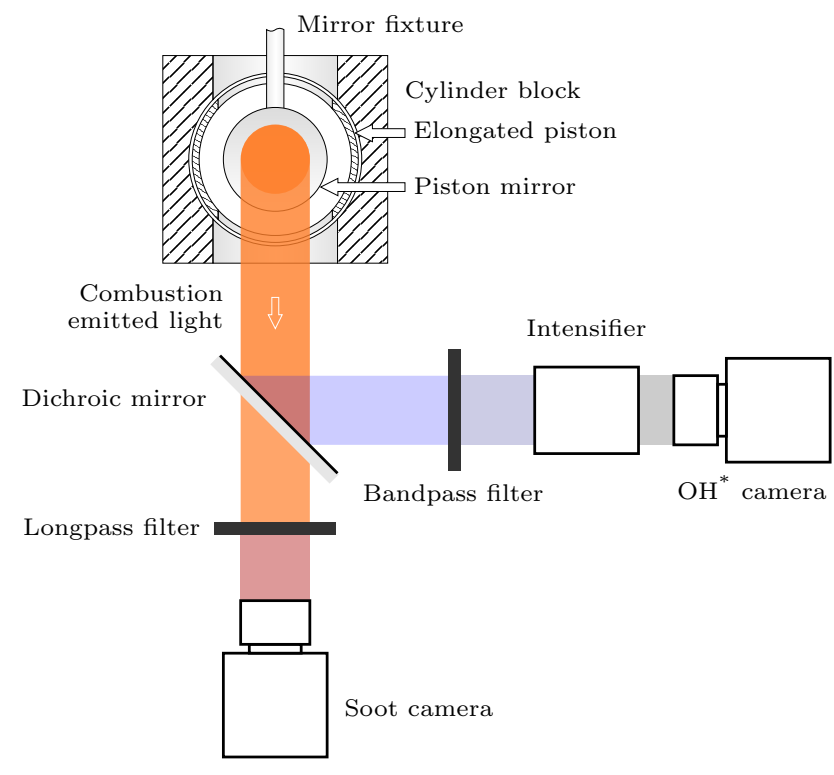

Figure 4: Diagram of the optics arrangement used to measure the $\mathrm{OH}^{*}$ chemiluminesence and soot incandescence. The arrangement is viewed from above. The location of the cut plane for the engine section shown is indicated by the $\mathrm{A}-\mathrm{A}$ cut plane in Figure 1.

intensifier equipped with UV transmitting 100 [mm] lens set to $\mathrm{f} / 1.4$ was used as a sensor for the luminescence transmitted through the bandpass filter. The intensifier amplified the transmitted luminescence and the output of the intensifier was recorded using a Vision Research v7.1 video camera, designated as the $\mathrm{OH}^{*}$ camera.

The luminescence and incandescence transmitted through the dicroich mirror was filtered with a longpass filter with a cut on wavelength of 610 [nm]. This filtered the luminescence from Na observed in the spectrum measurements. The filtered broadband radiation was recorded with a Vision Research Miro M310 video camera, designated as the soot camera. The cameras were frame synchronized and operated with the same frame frequency and exposure time as used for the spectrum camera during the spectrum measurements. Fifty cycles were recorded for each experiment.

\section{Cylinder Pressure Analysis}

Two engine loads were investigated in the experiments which were defined in terms of the injected fuel mass per cycle, denoted $m_{\mathrm{f}}[\mathrm{mg}]$, rather than the indicated mean effectice pressure. The injected fuel mass per cycle required for each of the two specified IMEP values of 3.6 [bar] and 5.8 [bar] at 1500 [RPM] with a single injection was determined by varying the injection duration length, the timing of the start of injection and the timing of the spark.

The IMEP and the IMEP coefficient of variation $(\mathrm{CoV})$ were calculated from cylinder pressure measurements recorded during 100 fired engine cycles for each combination of injection duration length, start of injection timing and start of the spark timing. The maximum IMEP for an injection duration was determined by varying the start of injection and the spark timing. The injection duration was increased until the maximum IMEP was equal to the given IMEP value for each of the two engine loads. The fuel mass corresponding to the injection duration length was determined from the coriolis fuel mass flow rate meter and the engine revolution frequency. An injected fuel mass per engine cycle of 18 [mg] and 26 [mg] was determined for the IMEP values of 3.6 [bar] and 5.8 [bar] respectively. The air to fuel ratio (AFR) relative to the stoichiometric ratio, denoted $\lambda[-]$ for the two fuel mass values were measured as 2.6 and 1.7 respectively.

The rate of combustion in terms of the rate of heat release, denoted $\frac{\mathrm{d} Q_{\mathrm{ch}}}{\mathrm{d} t}\left[\frac{\mathrm{J}}{\mathrm{s}}\right]$, the total combustion energy release in terms of the cumulative heat release, denoted $Q_{\text {ch }}[\mathrm{J}]$, and the combustion phasing in terms of the crank angle at which $50 \%$ of the total heat release occurs, denoted CA50 [CAD], was determined from the measured cylinder pressure, $p[\mathrm{~Pa}]$.

A polytropic coefficient was determined for the compression and expansion strokes using a linear least squares (LSQ) fit of $p V^{\kappa}=C$ where $C$ is a constant also determined in the LSQ fit. The polytropic coefficient between the compression and expansion strokes was determined from a linear interpolation of the compression and expansion polytropic coefficient. The polytropic coefficient was used to determine the rate of combustion using an energy conservation approach [38].

\subsection{Combustion Phasing}

The variation of work with combustion phasing is shown in Figure 5 and 6 as a plot of the sample mean IMEP, denoted $\overline{\mathrm{IMEP}}$ [bar] as a function of the sample mean CA50, denoted $\overline{\mathrm{CA} 50}$ [CAD] for the two load cases respectively with a single injection and $\omega=1500$ [RPM]. CA50 was calculated for each cycle and the average was calculated for $\overline{\mathrm{CA} 50}$. The results for several start of injection timings are shown for each engine load.

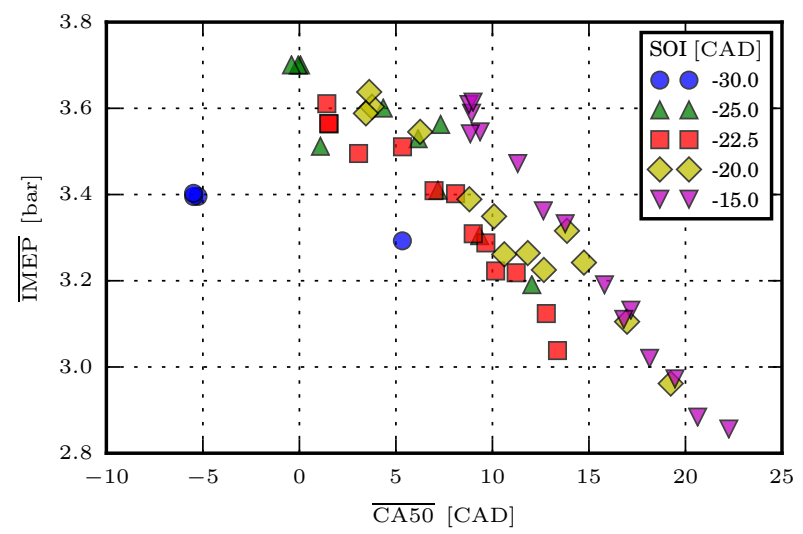

Figure 5: Variation of work (IMEP) with combustion phasing $(\overline{\mathrm{CA} 50})$ for $m_{\mathrm{f}}=18[\mathrm{mg}]$, a single injection and several SOI values. Mean of results for 100 fired cycles. 


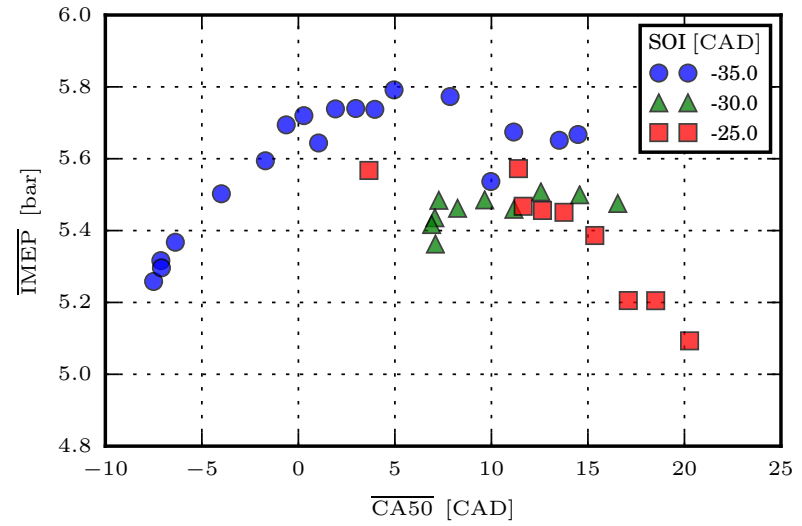

Figure 6: Variation of work ( $\overline{\mathrm{IMEP}})$ with combustion phasing $(\overline{\mathrm{CA} 50})$ for $m_{\mathrm{f}}=26[\mathrm{mg}]$, a single injection and several SOI values. Mean of results for 100 fired cycles.

The $\overline{\mathrm{CA} 50}$ value varied as a result of varying the start of the spark timing. The value of CA50 was found to be linearly proportional to the spark timing for all the start of injection timings investigated and both fuel mass values. As a result, the combustion phasing could be controlled using the spark timing.

For a cycle fuel mass of $18[\mathrm{mg}]$ the IMEP decreased as the value of CA50 increased for all start of injection timings, as shown in Figure 5. The earliest possible phasing of CA50 for each start of injection was limited by the earliest spark timing resulting in stable ignition and combustion which was $1[\mathrm{CAD}]$ after the start of injection resulting in CA50 occurring $25[\mathrm{CAD}]$ after the start of injection as shown in Figure 5. The maximum IMEP for each SOI occurred at the earliest possible CA50 both before and after TDC. The maximum IMEP measured occurred with $\mathrm{SOI}=-25[\mathrm{CAD}]$ and $\mathrm{CA} 50=-0.41[\mathrm{CAD}]$. The difference between the maximum IMEP for each of the start of injection timings was small when compared to the variation in IMEP with CA50. This suggests that the spark timing relative to the start of injection had the greatest effect on the IMEP for $m_{\mathrm{f}}=18[\mathrm{mg}]$ and a single fuel injection.

For a cycle fuel mass of 26 [mg], CA50 could be phased widely for the earliest start of injection at -35 [CAD] relative to later SOI. The maximum IMEP occurred with $\mathrm{SOI}=-35[\mathrm{CAD}]$ and $\mathrm{CA} 50=5.0[\mathrm{CAD}]$. The IMEP for $\mathrm{SOI}=-35[\mathrm{CAD}]$ was approximately constant in the CA50 interval 0 to $10[\mathrm{CAD}]$ and decreased as CA50 was advanced or postponed outside of the interval. The maximum IMEP for later start of injection timings was smaller and the earliest possible phasing of CA50 relative to the start of injection occurred later.

The combustion phasing resulting in the maximum work for the larger load was similar to homogeneous operation with typical optimal CA50 timings of 7 [CAD] [2]. This is in contrast to the optimal CA50 phasing for the low load case which occurred at TDC. These results are consistent with those reported by de Francqueville [22] where the CA50 resulting in maximum IMEP for E85 was found to increase with the engine load. In that study the CA50 for the maximum IMEP occurred prior to TDC for IMEP values of 2 [bar] and 5 [bar] and at TDC for 8 [bar]. The same trends were found for gasoline $[22,13,8]$.

The effect of the delay between injection and the spark on combustion variability is shown in Figure 7 and 8 for $1500[\mathrm{RPM}]$ and each of the two cycle fuel quantities respectively. The indicated mean effective pressure coefficient of variation, IMEP CoV, is plotted as a function of the crank angle delay between the start of injection and the start of the spark (SOS - SOI).

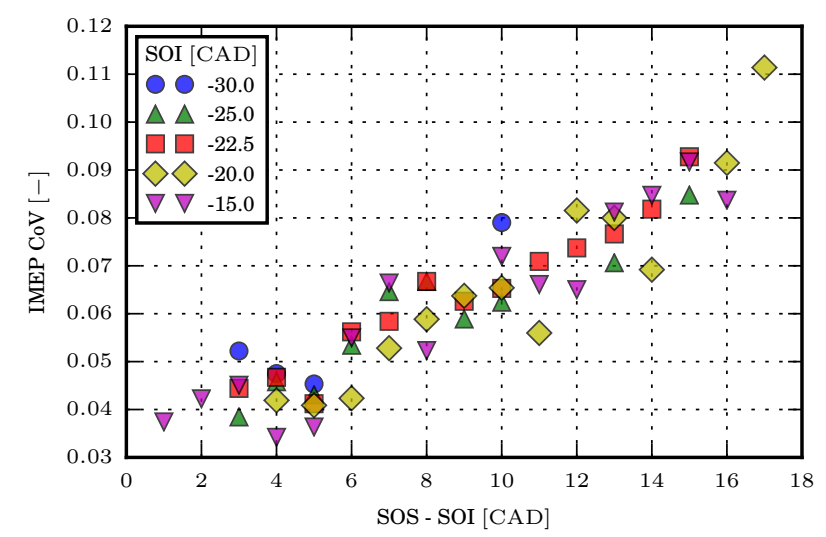

Figure 7: Combustion variability (IMEP CoV) as a function of the delay between the start of injection and the start of the spark (SOS SOI) for $\omega=1500[\mathrm{RPM}], m_{\mathrm{f}}=18[\mathrm{mg}]$, a single injection and several SOI values. IMEP CoV determined from 100 fired cycles.

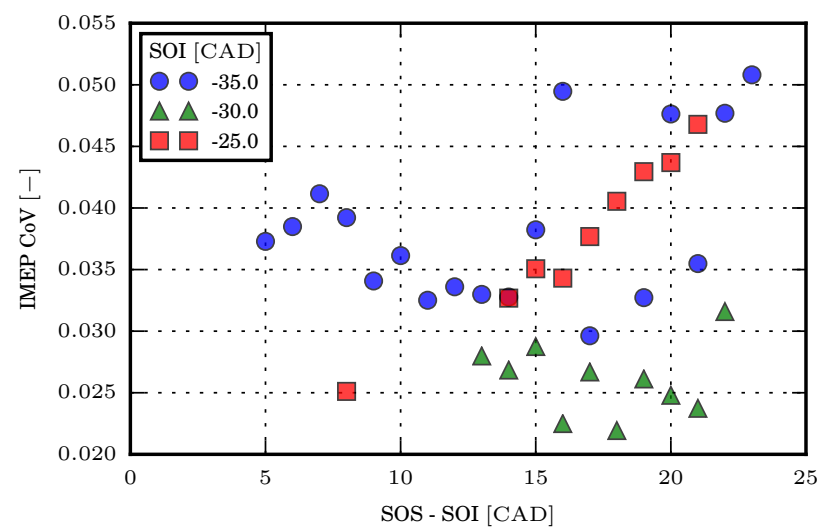

Figure 8: Combustion variability (IMEP $\mathrm{CoV}$ ) as a function of the delay between the start of injection and the start of the spark (SOSSOI) for $\omega=1500[\mathrm{RPM}], m_{\mathrm{f}}=26[\mathrm{mg}]$, a single injection and several SOI values. IMEP CoV determined from 100 fired cycles.

For the $m_{\mathrm{f}}=18[\mathrm{mg}]$ engine load and all start of injection timings the IMEP CoV increased with the delay between the start of injection and the start of the spark. Ignition could not be achieved with spark timing at or prior to the start of injection indicating that the leading edge of the fuel spray could not be ignited. This stands in contrast to the ignition of the leading edge E85 plumes 
from a multi hole injector in the investigation by Sjöberg and Reuss [9]. The lowest IMEP CoV for all cases was observed in the 3 to 5 [CAD] SOS - SOI delay interval. The spark delay range is approximately equal to that used by Hemdal et al. [13] and Oh and Bae [8] to achieve stable ignition of gasoline from outward opening piezo injectors. For $m_{\mathrm{f}}=26[\mathrm{mg}]$ the majority of IMEP CoV measurements were smaller than for the cases involving a smaller cycle fuel mass. The IMEP $\mathrm{CoV}$ did not increase in the manner observed for $m_{\mathrm{f}}=18$ [mg]. The maximum IMEP $\mathrm{CoV}$ for each start of injection occurred with the latest spark timings.

\subsection{Injection Strategy}

The start of injection and spark timings used in the optical measurement experiments are given in Table 3 with combustion variable results from cylinder pressure measurements performed during imaging of combustion. The measurements were performed after the combustion phasing measurements discussed in the preceding section. The difference in IMEP between the results presented in Section 3.1 and this section were caused by replacement of the piston rings and different ambient conditions.

The start of injection and spark timings for the single injection experiments were chosen in order to maximise the measured mean IMEP and secondly to minimise the IMEP CoV. The timing of the injection and spark signals for each of the experiments in Table 3 is illustrated in Figure 9. The spark was timed to occur immediately prior to the end of the injection of fuel for the $m_{\mathrm{f}}=18$ [mg] and single injection experiments. The fuel spray was directly ignited by the spark as a result of the spark timing, as is also discussed in Section 4. The fuel spray from a single injection of 26 [mg] of fuel could not be ignited directly while the fuel spray was passing the spark plug. Ignition was achieved with a spark beginning after the fuel spray had passed the spark plug.

The injections were of equal length in each of the experiments with multiple fuel injections in a cycle. The sum of the injection durations was greater than the duration in the corresponding single injection experiments. The difference was due to the time required for the additional opening and closing of the injector pintle.

In all of the multiple injection experiments, the fuel spray from one of the multiple injections was ignited directly at the end of the injection. In all but one of the multiple injection experiments, the fuel spray from the last injection was ignited. In the one experiment where this was not the case, the fuel spray from the first of two injections was ignited.

Fuel sprays from injections with an injection trigger signal duration of $560[\mu \mathrm{s}]$ or shorter could be ignited directly by a spark occuring while the fuel spray impinged on and passed by in close vicinity of the spark plug. The fuel spray from an injection with an injection trigger signal duration of $760[\mu \mathrm{s}]$ could not be ignited directly in the same manner. This indicates that a maximum single injection

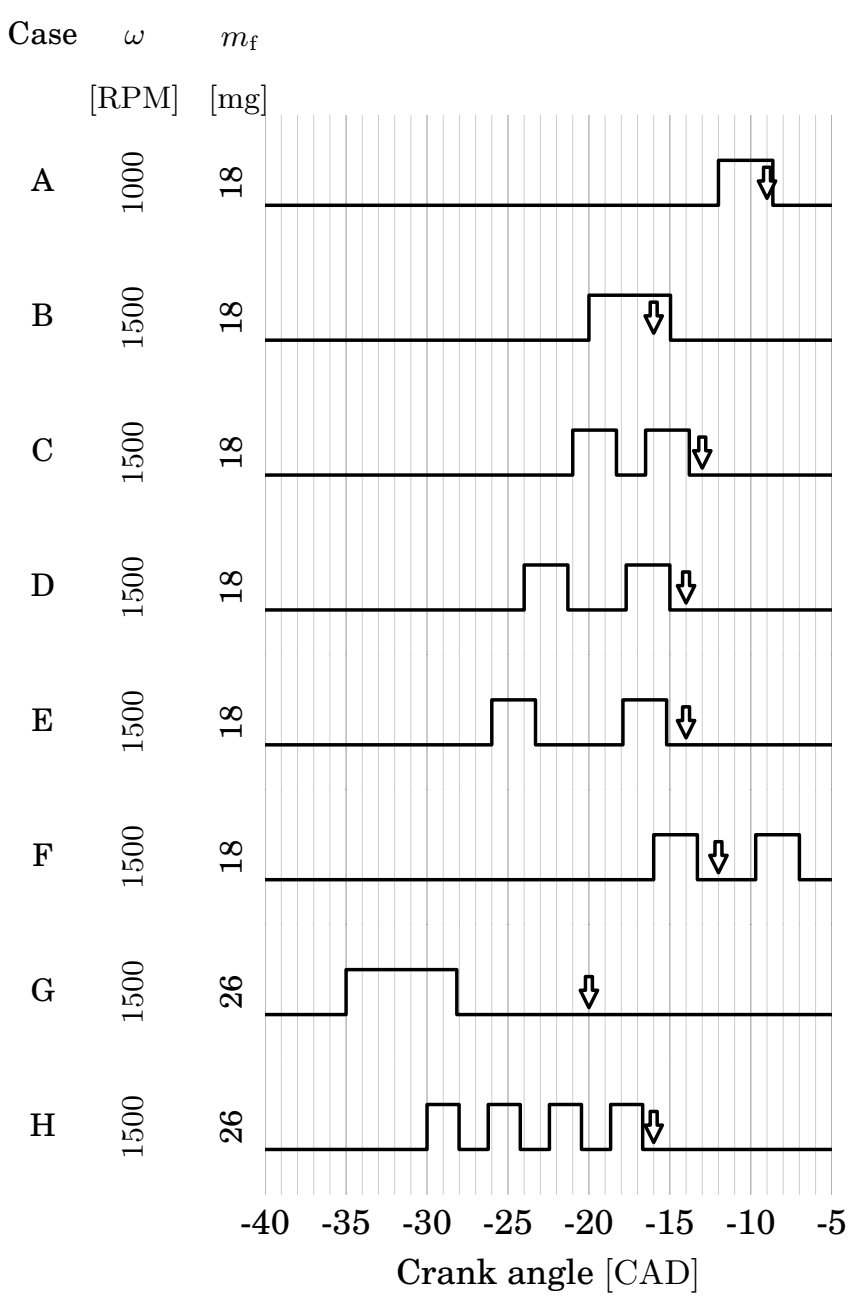

Figure 9: Diagram of the injection and ignition coil trigger signal timings and durations for the experiments in Table 3. A high signal indicate an injection trigger signal. The arrows indicate the timing of the ignition coil trigger signal. 


\begin{tabular}{|c|c|c|c|c|c|c|c|c|c|c|c|c|c|c|}
\hline $\begin{array}{l}\text { Case } \\
{[\mathrm{RPM}]}\end{array}$ & {$[\mathrm{mg}]$} & $\begin{array}{l}m_{\mathrm{f}} \\
{[-]}\end{array}$ & $\begin{array}{c}n_{\mathrm{inj}} \\
{[\mathrm{CAD}]}\end{array}$ & $\begin{array}{l}\text { SOI } \\
{[\mu \mathrm{s}]}\end{array}$ & $\begin{array}{l}t_{\mathrm{inj}} \\
{[\mu \mathrm{s}]}\end{array}$ & $\begin{array}{l}d_{\text {inj }} \\
{[\mu \mathrm{s}]}\end{array}$ & $\begin{array}{c}d_{\text {inj }} \\
{[\mathrm{CAD}]}\end{array}$ & $\begin{array}{l}\text { SOS } \\
{[\mathrm{bar}]}\end{array}$ & $\begin{array}{c}\overline{\text { IMEP }} \\
{[\%]}\end{array}$ & $\begin{array}{c}\Delta \overline{\mathrm{IMEP}} \\
{[\%]}\end{array}$ & $\begin{array}{c}\text { IMEP } \\
\text { CoV } \\
{[\%]}\end{array}$ & $\begin{array}{c}\triangle \mathrm{IMEP} \\
\mathrm{CoV} \\
{[\mathrm{CAD}]}\end{array}$ & $\begin{array}{l}\overline{\mathrm{CA} 50} \\
{[\mathrm{CAD}]}\end{array}$ & $\begin{array}{c}\overline{\text { CA50 }}- \\
\text { SOS }\end{array}$ \\
\hline A & 1000 & 18 & 1 & -12 & 560 & & & -9 & 3.66 & 3.21 & & 3.4 & 12 & \\
\hline B & 1500 & 18 & 1 & -20 & 560 & & & -16 & 3.73 & (a) & 3.91 & (a) & 2.6 & 19 \\
\hline $\mathrm{C}$ & 1500 & 18 & 2 & -24 & 300 & 200 & 1.8 & -14 & 3.96 & $6.1_{(\mathrm{a})}$ & 3.24 & $-17_{(\mathrm{a})}$ & 3.2 & 16 \\
\hline D & 1500 & 18 & 2 & -24 & 300 & 400 & 3.6 & -14 & 3.97 & $6.4_{(\mathrm{a})}$ & 2.92 & -25 (a) & 3.1 & 17 \\
\hline $\mathrm{E}$ & 1500 & 18 & 2 & -24 & 300 & 600 & 5.4 & -14 & 3.93 & $5.4_{(\mathrm{a})}$ & 2.83 & -28 (a) & 2.7 & 17 \\
\hline $\mathrm{F}$ & 1500 & 18 & 2 & -16 & 300 & 400 & 3.6 & -12 & 4.07 & $9.1_{(\mathrm{a})}$ & 2.10 & -46 (a) & 3.2 & 15 \\
\hline G & 1500 & 26 & 1 & -35 & 760 & & & -20 & 4.97 & (b) & 5.33 & (b) & 1.9 & 22 \\
\hline $\mathrm{H}$ & 1500 & 26 & 4 & -30 & 220 & 200 & 1.8 & -16 & 5.25 & $5.6_{(\mathrm{b})}$ & 2.32 & $-56_{(\mathrm{b})}$ & 1.1 & 17 \\
\hline
\end{tabular}

Table 3: Case injection parameter values and the measured work and combustion variable results for the experiments. The combustion variable results were determined from cylinder pressure measurements during imaging. The change in mean IMEP and IMEP CoV for multiple injection experiments relative to the single injection experiment are denoted $\Delta \overline{\mathrm{IMEP}}[\%]$ and $\Delta \mathrm{IMEP}$ CoV [\%] respectively. The $\Delta \overline{\mathrm{IMEP}}$ and $\triangle \mathrm{IMEP} \mathrm{CoV}$ value subscripts denote the label of the single injection experiment to which the value is relative to.

duration existed for the stable ignition of the fuel spray. The ignition coil trigger signal timing and the injection trigger signals for the single and multiple injection experiments are illustrated in Figure 9. The injector began to open and close at the start and end of an injection trigger signal respectively. The injection of fuel continued for a fixed duration after the end of the injector trigger signals illustrated in Figure 9 as a result of the time required for the injector to close after the end of the injection trigger signal.

The mean IMEP was larger and the IMEP CoV was smaller in all multiple injection experiments relative to the values for the corresponding single injection experiments. The mean IMEP and IMEP CoV measured for multiple injection experiments relative to the corresponding single injection experiment, denoted $\Delta \overline{\mathrm{IMEP}}$ and $\Delta$ IMEP CoV respectively, are given in Table 3 . The delay between two injections did not affect the mean IMEP or IMEP CoV in the experiments with a 18 [mg] cycle fuel mass. The largest IMEP and smallest IMEP CoV in the experiments with $m_{\mathrm{f}}=18$ [mg] was measured in the experiment with $\mathrm{SOI}=-16[\mathrm{CAD}]$ and $\mathrm{SOS}=-12[\mathrm{CAD}]$ which resulted in ignition of the fuel spray from the first injection. The $9.1[\%]$ increase in the mean IMEP and a 46 [\%] decrease in IMEP CoV was measured relative to the single injection experiment. The increase in IMEP and decrease in IMEP $\mathrm{CoV}$ was smaller when the second fuel spray was ignited. The increase in IMEP when the cycle fuel mass 26 [mg] was delivered in four injections and the last of the fuel sprays was ignited was of a similar magnitude to the experiments with the smaller fuel mass and the same fuel spray relative spark timing while relative reduction in IMEP CoV was twice as large.

Figure 10 shows the mean rate of heat release for the injection method and ignition timing combinations investigated for $m_{\mathrm{f}}=18[\mathrm{mg}]$ and $\omega=1500$ [RPM]. The mean heat release rate immediately after ignition and prior to -5 [CAD] was equal for all of the experiments. This was also the case during the latter stages of combustion after $10[\mathrm{CAD}]$. Ignition of the fuel spray from the first of two injections resulted in the maximum mean heat release rate

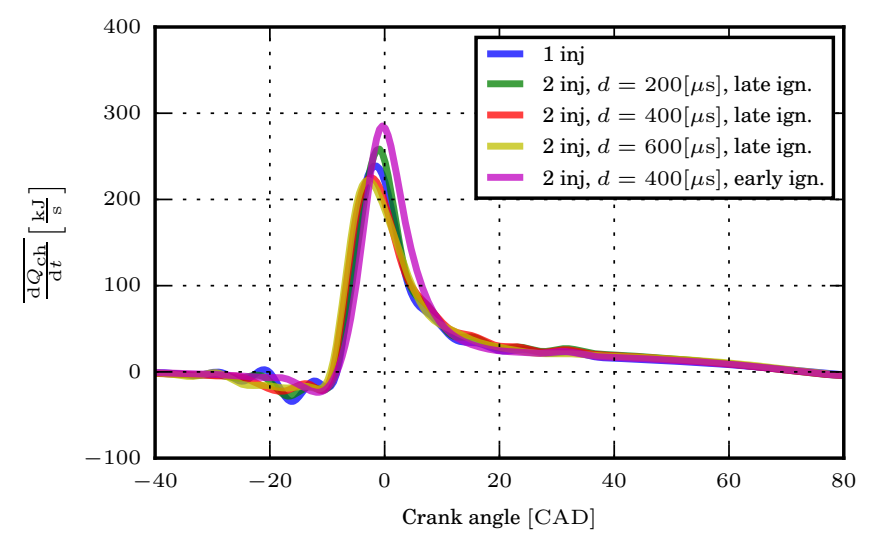

Figure 10: The rate of combustion for experiments B-F in Table 3 $\left(\omega=1500[\mathrm{RPM}], m_{\mathrm{f}}=18[\mathrm{mg}]\right)$. Mean of the cycle heat release rates for 100 cycles plotted as a function of crank angle.

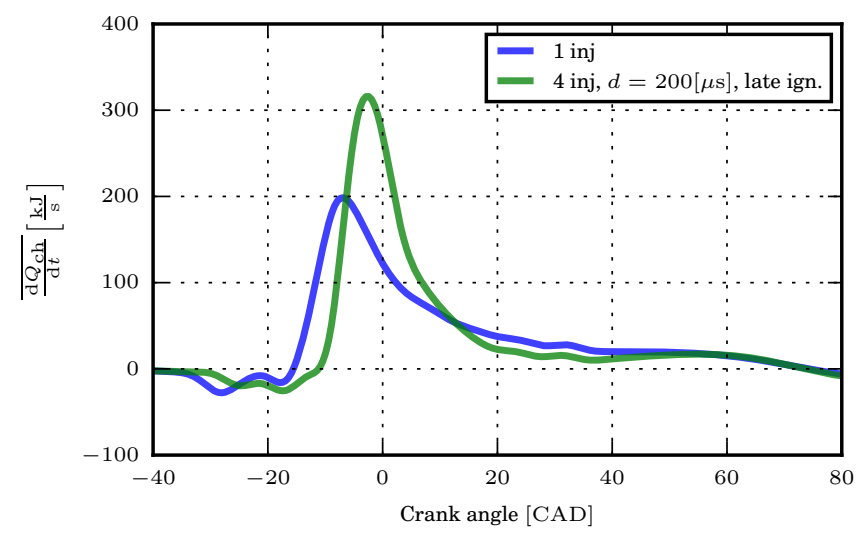

Figure 11: The rate of combustion for experiments $\mathrm{G}$ and $\mathrm{H}$ in Table $3\left(\omega=1500[\mathrm{RPM}], m_{\mathrm{f}}=26[\mathrm{mg}]\right)$. Mean of the cycle heat release rates for 100 cycles plotted as a function of crank angle. 


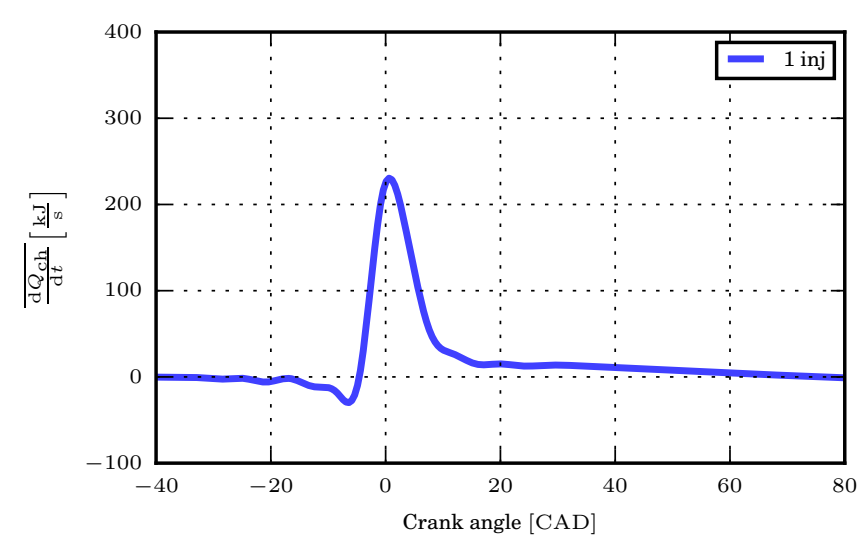

Figure 12: The rate of combustion for experiment $\mathrm{A}(\omega=$ $\left.1000[\mathrm{RPM}], m_{\mathrm{f}}=18[\mathrm{mg}]\right)$. Mean of the cycle heat release rates for 100 cycles plotted as a function of crank angle.

relative to the other injection method and ignition timing combinations in Figure 10. The maximum heat release rate was $285[\mathrm{~kJ} / \mathrm{s}]$ and occurred at $-0.4[\mathrm{CAD}]$. This was $19[\%]$ greater than the maximum heat release rate when a single injection was used. The maximum heat release rate was smaller when the fuel spray from the second of two injections with injection delays of 400 and $600[\mu \mathrm{s}]$ was ignited. The duration of the first half of the combustion process was longest for the single injection experiment. This indicated that the rate of heat release decreased at a greater rate from the maximum value in comparison to the split injection experiments as the IMEP was the smallest for single injection experiment.

Injecting $26[\mathrm{mg}]$ with a single injection resulted in a maximum rate of heat release $199[\mathrm{~kJ} / \mathrm{s}]$. This was smaller than the maximum observed for a cycle fuel mass of 18 [mg]. The heat release rate is shown in Figure 11. Delivering an equal fuel mass in four injections and igniting the last fuel spray caused the maximum heat release rate to increase to $316[\mathrm{~kJ} / \mathrm{s}]$. This was a $59[\%]$ increase relative to the single injection approach.

The maximum rate of heat release at $1000[\mathrm{RPM}]$ was equal to the corresponding single injection experiment at 1500 [RPM] as evident from comparison of Figure 12 with Figure 10 for the respective engine rotational frequencies. The time duration for combustion of the first half of the fuel mass was equal for both experiments. This indicates that an increase in cylinder gas turbulence due to an increase in engine rotational frequency had little effect on the initial combustion process [2].

The results of the multiple injection experiments for both cycle fuel mass values relative to the results for the single injection experiments demonstrate that multiple injections can significantly increase the IMEP and decrease the IMEP CoV. The maximum IMEP and minimum IMEP $\mathrm{CoV}$ was achieved when the first of multiple fuel sprays was ignited. As the cycle fuel mass increased the maximum mean rate of heat release decreased and the IMEP CoV increased when a single injection was used. The increase in the IMEP and decrease in the IMEP CoV with four injections relative to a single injection for the larger fuel mass was greater than achieved with multiple injections for the smaller fuel mass. Multiple injections are therefore required to avoid deterioration in the combustion rate and combustion stability as the fuel mass increases. An increase in the rate of heat release was also observed by Oh et al. [36] for gasoline when two injections were used instead of one.

\section{Single Injection Optical Measurements}

Optical measurement results for the single injection experiments listed in Table 3 are presented in this section. The injection and igntion timings for each of the experiments are illustrated in Figure 9.

\subsection{Imaging}

Time resolved images of the injection of fuel, spark ignition and combustion process are shown in Figure 13 for cycle number 50 of the experiment with $\omega=1500$ [RPM] and $m_{\mathrm{f}}=18[\mathrm{mg}]$. The images were recorded with the piston camera and liner camera. An LED backlight provided the illumination required prior to combustion for the piston and fuel spray to be visible. The LED trigger signal ended at the spark timing in order for the combustion luminescence to be visible in the images taken through the cylinder liner. The LED light decayed over 4 [CAD]. Intensity scaling was applied to images with a maximum intensity smaller than 0.25 of the full scale. The scaling is denoted in each image. The black horizontal line in the images recorded by the liner camera is due to a metal join between the optical cylinder liner and the cylinder head pent roof gable windows.

The fuel spray first becomes visible at -18.9 [CAD] in the piston image. The fuel spray scatters light towards the piston mirror and camera. The fuel spray creates a shadow in the liner camera images due to the scattering and absorption of the diffuse background illumination by the fuel spray. The spark plug protrusion shadows the fuel spray in the first image of the fuel spray. The hollow cone shape of the fuel spray is clear in the next image at $-18.4[\mathrm{CAD}]$. The hollow cone fuel spray consists in part of long liquid jets separated radially by gaps consisting of less dense fuel spray regions based. The liquid jets are discernible in the early hollow cone spray in the cylinder liner image at -18.4 [CAD]. The less dense hollow cone spray regions are visible in the cylinder liner image recorded fro-17.5 [CAD] to -15.7 [CAD] where the backlight is scattered more weakly and is visible. The liquid jets penetrate further than the rest of the hollow cone spray as shown in the cylinder liner image at -18.4 [CAD] and in the piston crown images recorded from -18.4 [CAD] to $-16.6[\mathrm{CAD}]$. Vortices at the leading edges of the hollow cone spray develop as the penetration length increases. The vortices are visible in the liner images at -17.5 [CAD] 


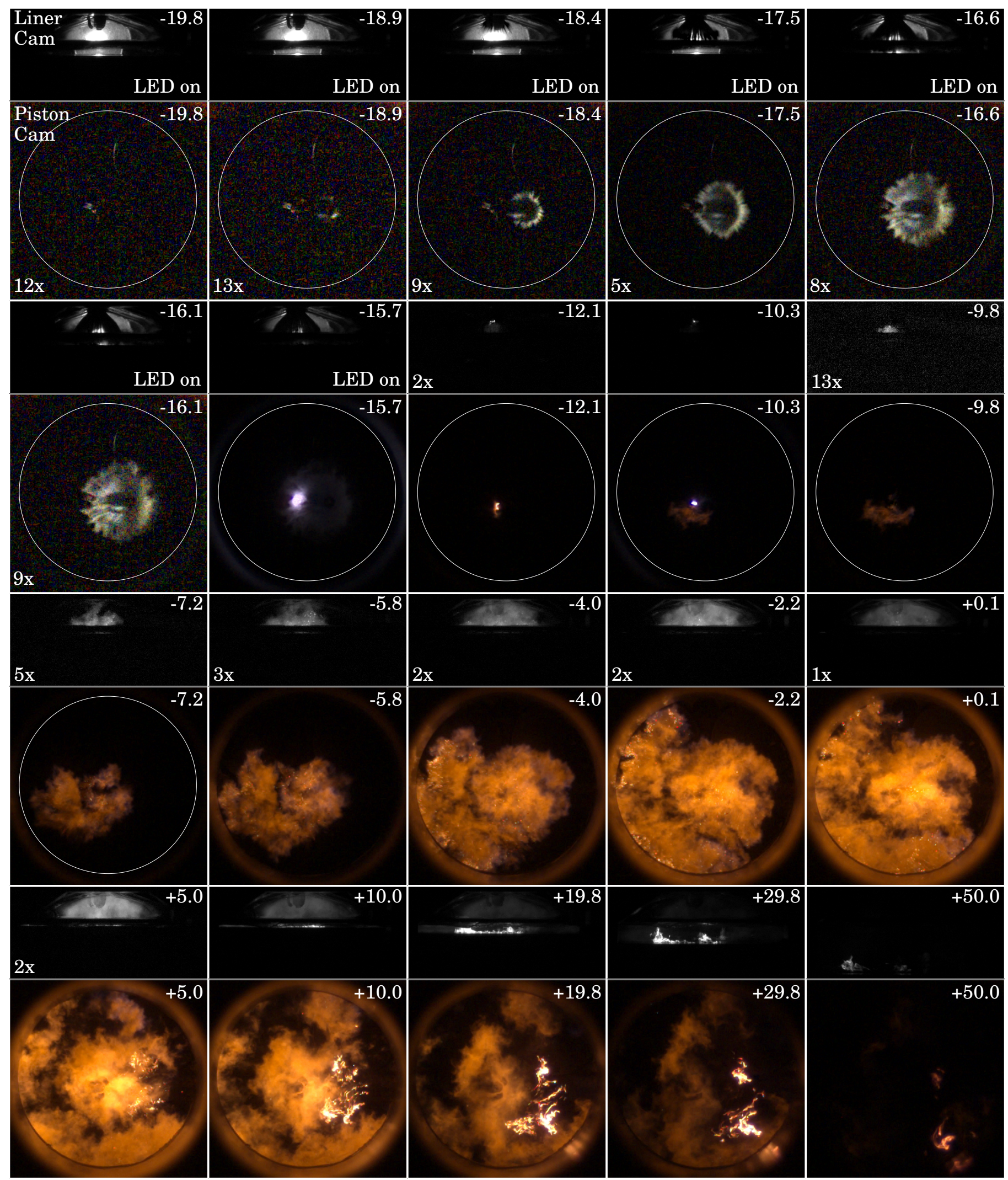

Figure 13: Imaging of the injection, ignition and combustion process for the case $\mathrm{B}\left(\omega=1500[\mathrm{RPM}], m_{\mathrm{f}}=18\right.$ [mg], a single injection, $\mathrm{SOI}=-20[\mathrm{CAD}], \mathrm{SOS}=-16[\mathrm{CAD}])$. Synchronously recorded piston and liner camera images of cycle number 50 . The crank angle is given in the top right corner of each image pair. Image intensity scaling is denoted in the bottom left corner of an image. The white circle in the piston camera images marks the edge of the piston crown window. 
and $-16.6[\mathrm{CAD}]$. The hollow cone fuel spray jets and vortices at the leading edges are consistent with the fuel spray structure observed in a spray chamber at 20 [bar] simulating stratified engine operation [17]. Mie scattering measurements indicated that the liquid jets were denser and penetrated further due to greater momentum. The spark plug casts a shadow on the left edge of the fuel spray. At $-16.6[\mathrm{CAD}]$ the fuel spray imginges on the spark plug at the location of the notch in the left edge of the fuel spray. The notch in the fuel spray due to spark plug impingement is also visible in the image recorded at -16.6 [CAD] and $-16.1[\mathrm{CAD}]$. The fuel spray impinged on the piston crown in the liner camera image recorded at -16.6 [CAD]. It can be assumed that it is the right edge of the fuel spray hollow cone in the piston image that impinges on the piston crown in the image recorded through the liner due to the angle of the fuel injector. More liquid fuel impinges on the piston crown as the injection of fuel continues and the piston approaches TDC.

The spark begins during the injection of fuel and ignites the fuel spray directly due to the fuel spray impinging on the spark plug. This is shown in the piston image recorded at -15.7 [CAD] in which the fuel spray is still discernable. The spark is obscured by the right side of the hollow cone in the liner image taken at the same instant. The spark continues to discharge energy as a flame develops at -12.1 [CAD] and -10.3 [CAD]. The flame expands from the spark plug towards the lower left quadrant of the piston images recorded from -10.3 [CAD] to 0.1 [CAD]. The peak line of sight flame area at 0.1 [CAD] conincides with the peak rate of heat release crank angle in Figure 10 for the single injection experiment.

Several voids within the outer flame boundaries are visible at $-7.2[\mathrm{CAD}]$. The voids between the visible flames indicate that several flames developed in an area with a non-uniform fuel distributions. Due to the nonuniform fuel distribution the fuel and air will have been partially mixed and several regions with a close to stoichiometric ratio of fuel and air are likely to have existed. The same void patterns with a smaller area are visible at $-5.8[\mathrm{CAD}]$. The decrease in void area from -7.2 [CAD] to $-5.8[\mathrm{CAD}]$ suggests that flame fronts expanded into the voids and that the voids contained a mixture of fuel and air with a leaner stoichiometry than the regions into which the flame propagated initially when coupled with a lack of luminous sooting flames. The lack of visible luminosity in the voids does not alone exclude reactions in the voids. Voids in the measured $\mathrm{OH}^{*}$ chemiluminescence in conjunction with the voids in visible combustion luminosity provides further evidence of areas devoid of ongoing reactions early in the combustion process as discussed in the following section. A non-uniform centered fuel distribution with several voids was observed using planar laser induced fluourescence of gasoline from an outward opening piezo actuated fuel injector [13]. These findings are not inconsistent with the conjecture of partially mixed combustion with flames fronts initially propogating through regions with fuel to air equivalence ratios ranging from near stoichiometric to fuel rich $[7,13]$. Voids appeared in the enflamed volume at -2.2 [CAD] and increased in area at 0.1 [CAD]. The voids consisted of combustion products since the void regions were enflamed prior to appearing. As combustion progressed further the contiguous flame at 0.1 [CAD] divided into several flames as seen in the images recorded at $5.0[\mathrm{CAD}]$ and $10.0[\mathrm{CAD}]$. The increase in the area of the flame at the top of the combustion chamber from $5.0[\mathrm{CAD}]$ to 10.0 [CAD] indicate the presence of mixed regions of fuel and air late in the combustion process signalled by the decrease in the total visible flame cross section area. The flame propagation behaviour as determined from combustion luminosity is consistent with the flame propagation in spray guided stratified combustion of E85 using a multihole injector [9].

Spots of intense luminosity were present on the left front of the flame at $-4.0[\mathrm{CAD}]$ and on the top left and bottom flame front at $0.1[\mathrm{CAD}]$. The luminous spots were relatively short lived as they do not persist from each image to the next image in the series. The luminous spots are not of sufficient extent or luminosity to be visible in the liner images. Luminous spots of a similar nature were observed in homogeneous engine operation. Fuel was injected at -360 [CAD] during homogeneous engine operation and liquid droplets in the gas phase are assumed to have vaporized prior to combustion as has been observed optically for E85 injection during the intake stroke using a multihole injector [18]. In the absence of fuel droplets the luminous spots can not stem from droplet combustion. The luminosity emitted from the burnt gases during homogeneous operation was green. This suggests that the luminous spots observed in Figure 13 were particles from the copper piston rings. The luminous spots were observed throughout the combustion chamber during homogeneous combustion in contrast to the stratified combustion in Figure 13 where the luminous spots are present primarily at the leading edges of flames.

Luminous spots appear to the right of the center of the combustion chamber at 5.0 [CAD] and continue to develop into flames at 10.0 [CAD] in the piston images. The maximum flame area in the piston images coincides with the onset of the relatively more luminous flames. The location of the luminous flames coincides with where the right edge of the fuel spray hollow cone impinges on the piston crown in the images recorded at -16.6 [CAD] and -16.1 [CAD]. The bottom of the luminous flames are located on the piston crown and follow the piston crown during the expansion stroke in the cylinder liner camera images recorded from $10.0[\mathrm{CAD}]$ to 50.0 [CAD]. Due to the location of the luminous flames in the piston and cylinder liner camera images the luminous flames are presumed to be diffusion flames created by the combustion of liquid fuel deposited on the piston crown by the impinging hollow cone fuel spray. The diffusion flames persist until after the main combustion has ended and are visible in the piston and liner images captured at 50.0 [CAD] in which they are the 
only significant source of luminosity. Liquid gasoline films deposited on the piston crown by fuel spray impingement due to injection late in the compression stroke have been observed for a centrally mounted low pressure swirl injector [11] an engine with wall guided stratified combustion using multihole and swirl injectors [10] and spray guided stratified combustion using a multihole injector [12]. Diffusion flames from the combustion of the piston fuel films, referred to as pool fires, were observed in all three studies. The diffusion flames in spray guided stratified gasoline combustion followed the piston crown in the same manner as shown in the liner images in Figure 13. Fuel film diffusion flames have also been observed for E85 in wall guided stratified operation [39]. Piston fuel films are expected due to the greater spray penetration length of ethanol in comparison to alkane fuels as discussed previously.

Piston impingement was also observed for the experiment with an engine rotational frequency of $\omega=1500$ [RPM] and a single injection of 26 [mg] of fuel and for the experiment at the lower engine rotational frequency of $\omega=$ $1000[\mathrm{RPM}]$ and a single injection of 18 [mg]. Pool fires on the piston crown at the location of the fuel spray impingement on the piston crown was observed in both cases. Fuel spray impingement on the piston crown could not be avoided in any of the single injection experiments by injecting fuel earlier in the compression stroke when the distance between the piston and the fuel injector was larger. Phasing the start of injection earlier resulted in unstable ignition and a reduction in IMEP as discussed in Section 3.1. Diffusion flames from the combustion of piston crown fuel films could therefore not be eliminated by advancing the start of injection to avoid fuel spray impingment on the piston crown. Phasing of the start of injection was not found to reduce the fuel smoke number (FSN) in spray guided stratified operation using a multihole injector [12]. A reduction in the FSN and the IMEP was observed in spray guided stratified combustion using an outward opening piezo injector with earlier phasing of the start of combustion[8] and was attributed to the increase in particulate emissions with injection delay towards to TDC to greater fuel-air stratification and shift in the equivalence ratio distribution towards lower values (fuel rich). The cylinder liner images in this study suggest that particulate emissions are at least in part due to piston crown pool fire diffusion flames such as those shown in Figure 13.

\subsection{Spectrum}

Images of the combustion luminescence (A) and combustion luminescence spectrum (B) passing through the piston crown synchronously recorded at $-14.0,0.0$ and 20.0 [CAD] in a cycle are shown in Figure 14. The spectrometer arrangement gathered luminesence from the combustion chamber volume delimited in the horizontal plane normal to the cylinder axis (a plane parallel to the piston crown surface) at the top of the combustion chamber by the white rectangle in the combustion luminescence images. The measurement volume approximately spanned the combustion diameter in the vertical direction and was centered horizontally on the spark plug. The measurement volume was spatially resolved in the vertical direction of the delimitation rectangle in the combustion luminescence images and correspondingly along the vertical axis in the combustion luminescence spectra images (B).

Luminescence from the spark discharge at the centre of the rectangle delimiting the measurement boundaries in the plane was observed at -14.0 [CAD], as shown in the luminescence image in (A). The spatially centered (vertical axis centre) broad spectrum in the luminescence spectrum image in (B) corresponds to the spark luminescence. Peaks in the spatial sum of the luminescence spectrum (C) correspond to energy transitions of species present at the spark plug. Given that the fuel spray was ignited as it passed the spark plug during the sparkplug discharge, the species present are in part the result of the combustion of fuel. Species with energy transitions corresponding to the wavelengths of the spectrum peaks in $(\mathrm{C})$ have been labeled in the figure.

$\mathrm{OH}$ and $\mathrm{CH}$ possess energy transitions in the vicinity of 312 [nm] at which a spectrum peak is present [31]. The spectrum peak at $312[\mathrm{~nm}]$ is attributed primarily to the presence of $\mathrm{OH}$ with contributions from $\mathrm{CH}$ and possibly other unidentified species and is referred to as $\mathrm{OH}^{*}$ chemiluminescence. Both $\mathrm{OH}$ and $\mathrm{CH}$ are radical species involved in the combustion reaction mechanism models for the combustion of hydrocarbon fuels in general and ethanol in particular [28, 29]. The presence of either is taken to indicate the occurrence of radical chemistry and conditions conducive to the oxidation of soot as discussed in Section 1.2. The blue shaded region indicates the spectrum interval gathered in the $\mathrm{OH}^{*}$ chemiluminescence imaging and spans a wavelength interval of 10 [nm] at FWHM centered at 308 [nm]. This wavelength interval covers the spectrum peak attributed to $\mathrm{OH}^{*}$ chemiluminescence with the peak located at the far end of the interval as shown in Figure 14. The $\mathrm{OH}^{*}$ chemiluminescence spectrum peak was also present at $0.0[\mathrm{CAD}]$ during the peak rate of heat release and at 20.0 [CAD] at which point two pool fires are visible in the luminescence image. The continued presence of $\mathrm{OH}^{*}$ chemiluminescence throughout the combustion process is consistent with the prescence of $\mathrm{OH}$ radicals in the coincident line of sight and visible flame fronts in the measurement volume apparent in the visible luminescence images (A) with $\mathrm{OH}$ radicals participating in ongoing combustion radical chemistry according to the discussed reaction mechanism models. The $\mathrm{OH}^{*}$ chemiluminescence intensity was centered and spread across the demarcated measurement area at 0.0 and 20.0 [CAD] coinciding with the visible flame area. This suggests flame front chemistry was distributed across the visible flame area. That $\mathrm{OH}^{*}$ chemiluminescence is easily identified and not obscured by spectrally broadband emission at 0.0 and 20.0 [CAD], demonstrates the applicability of luminescence at this wavelength for detection of rapid radical chemistry associated with flame fronts and conditions 

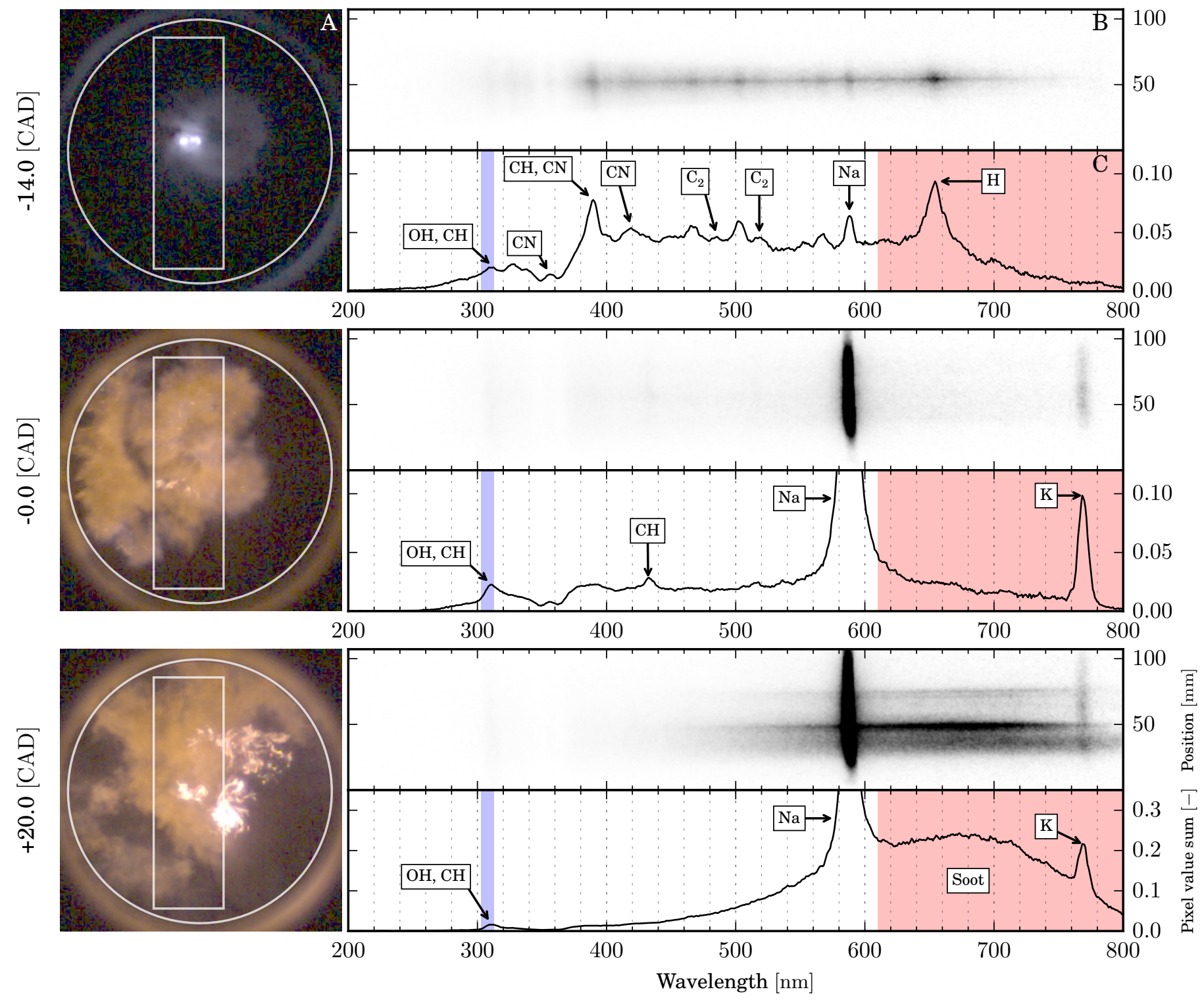

Figure 14: Images and spectra of luminescence passing through the piston crown recorded at $-14.0,0.0$ and 20.0 [CAD] for cycle number 45 of 50 fired cycles for case B $\left(\omega=1500[\mathrm{RPM}], m_{\mathrm{f}}=18[\mathrm{mg}]\right.$, one injection, SOI $=-20[\mathrm{CAD}]$ and SOS $\left.=-16[\mathrm{CAD}]\right)$. (A) Luminescence image. The white circle marks the location of the piston crown window edge. The white rectangle delimits the spectrometer measurement volume in the plane normal to the cylinder axis (the piston crown plane). The vertical axis of the measurement volume delimitation was spatially resolved in the luminescence spectrum. An exponential intensity transfrom with an exponent value of 0.25 has been applied to make the flame and low intensity details more easily visible. (B) The luminescence spectrum from the measured volume. The spectrum of the emitted luminescence is resolved along the horizontal axis of the image and the vertical location in the measurement volume delimitation rectangle in $(\mathrm{A})$ is resolved along the vertical axis. The position values are relative to the bottom edge of the delimiting rectangle. (C) Plot of the spatial sum of the emission spectrum image ((B) image column sums). The labels indicate species with energy state transitions corresponding to the wavelengths indicated by the label arrows. The blue and red shaded wavelength intervals (left and right respectively) were captured in the $\mathrm{OH}^{*}$ chemiluminescence and soot incandescence images respectively discussed in Section 4.3 and Section 5.2 using the experiment apparatus arrangement discussed in Section 2.4 . 
favourable for the oxidation of soot.

The large peak at $390[\mathrm{~nm}]$ is attributed primarily to $\mathrm{CH}$ and $\mathrm{CN}$ in addition to the probable luminescence contributions from other species. Both $\mathrm{CN}$ and $\mathrm{C}_{2}$ radicals are similarly attributed to several peaks as shown in Figure 14 and are also involved in hydrocarbon combustion reaction mechanism models. In contrast to $\mathrm{OH}^{*}$ chemiluminescence, the luminescence spectrum peaks to which $\mathrm{CN}$ and $\mathrm{C}_{2}$ are attributed are not easily identifiable at 0.0 and 20.0 [CAD] in part due to broadband emission from soot amongst other sources as discussed in the following.

$\mathrm{H}$ is thought to be one possible source for part of luminescence peak at $654[\mathrm{~nm}]$. The luminescence peak was present during the spark discharge and was not subsequently apparent at later stages of the cycle. The spectrum peak at $588[\mathrm{~nm}]$ is attributed to Na. The intensity of the spatial luminescence sum increased from -14.0 [CAD] to 20.0 [CAD] as combustion progressed and the flame front expanded. During the same period a spectrum peak at 768 [nm] attributed to $\mathrm{K}$ appeared and the intensity of this luminescence spectrum peak increased in the same manner as the peak associated with Na. Luminescence from both attributed sources spanned the vertical length of the visible flame area in the measurement boundaries at 0.0 and 20.0 [CAD]. Na luminescence thus accounts for the orange colour of the visible flame area. The source of $\mathrm{Na}$ and $\mathrm{K}$ is believed to be the fuel and the refining process of the fuel.

The bright luminescent flames approximately in the center of the chamber at 20.0 [CAD] emanated from pools fires as discussed in the preceding Section 4.1. Three areas of luminescence from pool fires occurred within the measurement volume. The pool fire luminescence in the center of the measurement boundary area gave rise to the broad saturated spectrum line (horizontal line) centered spatially (vertically) in the spectrum image. The pool fires above and below the central pool fire with approximately equal intense luminosity give rise to the less intense broad spectrums above and below the saturated broad spectrum line in $(\mathrm{C})$ due to their location on the right edge of the measurement volume. The broad spectrum lines in the luminescence spectrum image (B) results in a broad spectrum peak in the spatial sum of the luminescence spectrum (C). The spectral distribution of the broad spectrum peak is similar in nature to the distribution of the spectrum from blackbody radiation when the superimposed peaks from $\mathrm{Na}$ and $\mathrm{K}$ are disregarded. Based on this, the source of the broad spectrum peak is conjectured to be thermal radiation from particulate matter which in turn is conjectured to be soot particles. The spectral distribution is consistent with typical emission spectrums from soot [40, Ch. 12]. The red shaded area in luminescence spectrum spatial sum plots $(\mathrm{C})$ indicates the spectral region transmitted by the lowpass filter used for the soot incandescence imaging. The spectral sum of the soot incandescence transmitted by the filter is significantly greater than than the sum of the transmitted luminescence at -14.0 and $0.0[\mathrm{CAD}]$ from sources of luminescence other than broad spectrum soot incandescence at 20.0 [CAD]. It is for this reason that significant luminosity in the spectral interval gathered by the soot incandescence imaging is attributed primarily to soot with additional contributions from other sources of luminescence.

\section{3. $\mathrm{OH}^{*}$ Chemiluminescence and Soot Incandescence}

The cycle and crank angle resolved spatial distribution of $\mathrm{OH}^{*}$ chemiluminescence and soot incandescence and frequency was determined from the luminescence images recorded using the experiment arrangement detailed in Section 2.4. An average $\mathrm{OH}^{*}$ and soot luminesence background image at each crank angle was calculated from the images recorded prior to firing the engine. The average background image at each crank angle was subtracted from the images recorded during engine firing resulting in a set of background corrected images. A binary image was created for each background corrected image by application of a constant threshold value to the background corrected image. Two constant threshold values were used seperately for the $\mathrm{OH}^{*}$ chemiluminescence and soot incandescence images respectively. The same two threshold values were used for all experiments.

The binary images for all cycles at each crank angle were summed. The pixel values of the image sum for each crank angle is equal to the number of cycles in which luminescence exceeding the threshold value was detected along the line of sight through the combustion chamber cross section location corresponding to the image pixel. The image sum pixel value is a measure of the probability of luminescence at the given location. The spatial distribution of $\mathrm{OH}^{*}$ chemiluminescence and soot incandescence measured for 50 cycles in the experiment with $\omega=1500[\mathrm{RPM}]$ and $m_{\mathrm{f}}=18[\mathrm{mg}]$ and a single injection is shown in Figure 15 and the cycle averaged spatially summed $\mathrm{OH}^{*}$ chemiluminescence and soot incandescence as a function of the crank angle is shown in Figure 16.

$\mathrm{OH}^{*}$ chemiluminescence was measured in a region centered around the spark plug at the start of the spark $(-16.0[\mathrm{CAD}])$ in Figure 15 in the majority of cycles. The location and area of the $\mathrm{OH}^{*}$ chemiluminescence corresponds with the spark luminescence in the fuel spray in the piston crown image taken at -15.7 [CAD] in Figure 13. The extent of the $\mathrm{OH}^{*}$ chemiluminescence is in part caused by scattering of the intense chemiluminescence by the fuel spray as also occurs in general with the spark discharge luminosity in Figure 13. Given that $\mathrm{OH}^{*}$ is involved in combustion reaction mechanisms as discussed in Section 1 this indicates repeatable ignition of the fuel spray and is consistent with the stable combustion observed for this experiment as indicated by the small IMEP CoV value in Table 3. The $\mathrm{OH}^{*}$ chemiluminescence emitted during ignition lasted approximately $5[\mathrm{CAD}]$ as indicated by the low peak in Figure 16 and corresponds to the length of the spark discharge seen in the piston camera images. Soot in- 


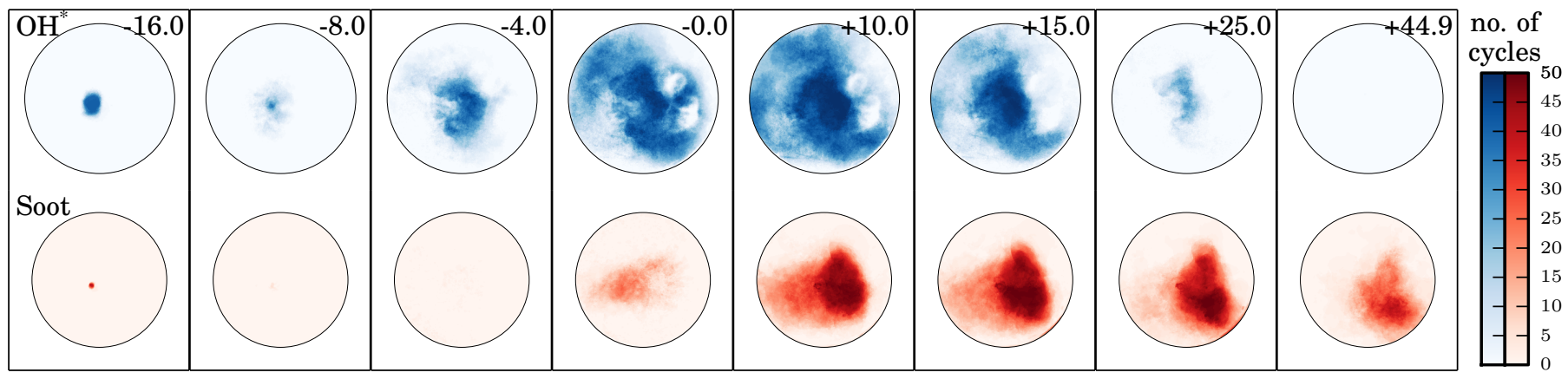

Figure 15: The spatial distribution and frequency of $\mathrm{OH}^{*}$ chemiluminescence and soot incandescence for case $\mathrm{B}\left(\omega=1500[\mathrm{RPM}], m_{\mathrm{f}}=\right.$ $18[\mathrm{mg}]$, one injection, $\mathrm{SOI}=-20[\mathrm{CAD}]$ and $\mathrm{SOS}=-16[\mathrm{CAD}])$. Sum of thresholded $\mathrm{OH}^{*}$ and soot incandescence images recorded for 50 cycles. The crank angle at which the images were recorded is denoted in the top right corner of each pair of images. The black circles mark the edge of the piston crown window. The images have been clipped to the area inside the piston crown window.

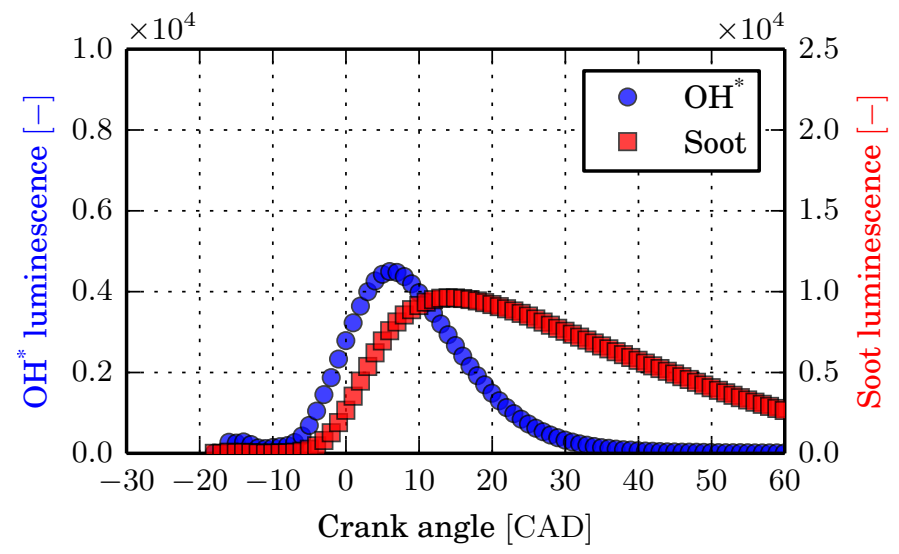

Figure 16: Total $\mathrm{OH}^{*}$ chemiluminescence and soot incandescence intensity during combustion for case $\mathrm{B}\left(\omega=1500[\mathrm{RPM}], m_{\mathrm{f}}=\right.$ $18[\mathrm{mg}]$, one injection, $\mathrm{SOI}=-20[\mathrm{CAD}]$ and $\mathrm{SOS}=-16[\mathrm{CAD}])$. Cycle average of the spatially summed intensity of 50 cycles as a function of crank angle recorded.

candescence occurred at the same location with the same repeatability and a smaller area.

The total $\mathrm{OH}^{*}$ chemiluminescence decreased immediately after the end of the spark discharge with a duration of $5[\mathrm{CAD}]$. The total $\mathrm{OH}^{*}$ chemiluminescence increased again at $-10[\mathrm{CAD}]$. Soot incandescence with an intensity greater than the threshold was absent after ignition as shown at $-8.0[\mathrm{CAD}]$ and $-4.0[\mathrm{CAD}]$. The increase in $\mathrm{OH}^{*}$ chemiluminescence and absence of soot incandescence suggests that early flame propagation occurred in absence of significant soot formation. Based on this the local stoichiometry in the flame propagation regions is assumed to have been stoichiometric to fuel lean given that fuel rich conditions are required for the formation of soot. The total $\mathrm{OH}^{*}$ chemiluminescence and area continued to increase in conjunction with increasing soot incandescence after $-4.0[\mathrm{CAD}]$ suggesting that the flame propagated into regions with a fuel rich stoichiometry in addition to regions with near stoichiometric fuel and air compositions. At 0.0 [CAD] the soot incandescence was absent in the regions with $\mathrm{OH}^{*}$ occurring in the majority of cycles and occurred with low frequency in the other regions with $\mathrm{OH}^{*}$ chemiluminescence occuring less frequently. The absence of the initial soot incandescence in the gas phase is attributed to oxidation due to conducive conditions implied by $\mathrm{OH}^{*}$ chemiluminescence.

The $\mathrm{OH}^{*}$ chemiluminescence peaked at 4.0 [CAD]. At $4.0[\mathrm{CAD}]$ soot incandescence appeared at the fuel spray impingement location due to beginning diffusion combustion of the liquid fuel films on the piston crown. The soot incandescence sum and the extent of the soot incandescence from the liquid fuel film diffusion combustion to increase as the $\mathrm{OH}^{*}$ chemiluminescence sum decreased with the total soot incandescence reaching a maximum at 14 [CAD]. Oxidation of soot continued while $\mathrm{OH}^{*}$ decreased and was particularly effective in the pool fire region from $10[\mathrm{CAD}]$ to 20 [CAD]. Soot formation in the pool fire region continued after the end of the $\mathrm{OH}^{*}$ chemiluminescence and conditions conducive to soot oxidation at 30 [CAD]. The increasing soot formation from the piston pool fires in the absence of conditions suitable for the oxidation of the soot is consistent with the almost constant rate of decrease in the total soot incandescence despite the effective initial oxidation of soot and decreasing cylinder temperature which both cause the soot incandescence sum to decrease $[7,13]$. The results suggest that soot was oxidized in the partially premixed combustion in the gas phase. Soot formation from pool fires initially occurred in conditions conducive to soot oxidation but continued after the conditions ended as indicated by the absence of $\mathrm{OH}^{*}$ chemiluminescence. In wall guided stratified combustion of gasoline measured an increasing total soot density from piston pool fires as the total soot density from the partially premixed combustion decreased resulting in a second total soot density peak [7]. The total $\mathrm{OH}^{*}$ chemiluminescence increased as the pool fire soot density peaked which has not been observed in the present case. The $\mathrm{OH}^{*}$ chemiluminescence reached a maximum after the maximum total soot incandescence using gasoline and soot incandescence decreased rapidly coinciding with the $\mathrm{OH}^{*}$ maximum despite increasing cylinder temperatures in the study by [13]. Combustion was phased early in this study in an attempt 
to avoid piston pool fires.

Circular voids in the $\mathrm{OH}^{*}$ chemiluminescence are visible beginning at 0.0 [CAD] and persist until 20.0 [CAD]. The pattern of the voids is consistent with the pattern of the soot deposits from pool fires on the piston crown. The soot deposits obstructed $\mathrm{OH}^{*}$ chemiluminescence and caused the voids. The piston crown soot pattern consisted of overlapping hollow ellipses which are particularly clear at $4.0[\mathrm{CAD}]$. The soot thickness was smaller in the center of the ellipses allowing chemiluminescence through. The soot pattern is thought to stem from the liquid jets in the portion of the hollow cone spray impinging on the piston crown depositing a greater amount of liquid fuel on the piston compared to the less dense and lower momentum fuel spray between the jets. Mie scattering measurements in the radial plane by [17] 15 [mm] from the injector at a time corresponding to 7 [CAD] after the start of injection at $\omega=1500$ [CAD] showed the a fuel spray density distribution reminiscent of the piston crown soot pattern visible in the $\mathrm{OH}^{*}$ chemiluminescence. The hollow ellipses piston crown soot pattern is similar to the soot deposits shown by [23] on a flat quartz piston crown in a piston bowl after spray guided stratified combustion of E85 using an 8-hole fuel injector. The soot deposits consisted of 8 hollow ellipses arranged in a circle where the E85 spray jets impinged. The conjecture of hollow cone liquid jets impinging on the piston crown and depositing liquid fuel in an ellipse pattern in this study is consistent with these results.

Several voids in the $\mathrm{OH}^{*}$ chemiluminescence not due to soot deposits on the piston were detected beginning early in the propagating flame at -4.0 [CAD] continuing until $10.0[\mathrm{CAD}]$. The voids are regions in which $\mathrm{OH}^{*}$ chemiluminescence occurred with lower frequency. The voids occurred in regions with low soot incandescence frequency values. Regions in close proximity to the voids with large $\mathrm{OH}^{*}$ chemiluminescence despite equal soot incandescence frequencies exist and for this reason the voids are not attributed to attenuation of the $\mathrm{OH}^{*}$ chemiluminescence by soot particles through scattering and absorption. The arc of large frequency $\mathrm{OH}^{*}$ chemiluminescence and void at the center of the arc at $-4.0[\mathrm{CAD}]$ persisted until 0.0 [CAD] while the extent of the chemiluminescence increased indicating that the flame propagated in other regions given the role of $\mathrm{OH}^{*}$ in fuel oxidation as discussed previously. The cycle frequency of $\mathrm{OH}^{*}$ chemiluminescence in the void in the center of the arc increased at 4.0 [CAD] as the flame propagated into the region repeatedly. Due to the initial absence of flame propagation into the void while flame propagation occurred in other regions and subsequent by $\mathrm{OH}^{*}$ chemiluminescence and soot incandescence in the void region occuring with a large frequency it is conjectured that a fuel rich mixture was present in the center void region on a repeated basis. A coincidental absence of $\mathrm{OH}^{*}$ chemiluminescence and soot incandescence in all cycles in regions at the bottom and top left of the combustion chamber indicates the absence of flame propagation into these regions. These results provide further confirmation of combustion in a partially mixed fuel and air mixture as a consequence of limited fuel and air mixing during and after fuel injection and prior to the end of combustion. The flame in each cycle is conjectured to have initially propagated in near stoichiometric regions and later propagated into both fuel lean and rich regions. If this is indeed correct, the voids completely devoid of $\mathrm{OH}^{*}$ indicate regions in which a self propagating flame could not be sustained due to either a sufficiently fuel lean local stoichiometry or the absence of fuel. The flame propagation behaviour as determined from $\mathrm{OH}^{*}$ chemiluminescence is consistent with the flame propagation results in wall guided stratified combustion of gasoline presented by [7].

\section{Multiple Injections Optical Measurements}

\subsection{Imaging}

A comparison of the fuel sprays from a single injection and double injection of 18 [mg] is shown in Figure 17 in the left and right columns respectively with cycle average cylinder liner images. The time from the start of the first injection trigger signal to the end of the last injection trigger signal was $560[\mu \mathrm{s}]$ and $1000[\mu \mathrm{s}]$ respectively and the time from the start of the first injection trigger signal, denoted $\Delta t_{\text {SOI }}[\mu \mathrm{s}]$, is given in each image. The end of the last trigger signal for both of the experiments occurred at the same crank angle as shown in Figure 9. At $\Delta t_{\mathrm{SOI}}=287[\mu \mathrm{s}]$ the penetration length of both fuel sprays was approximately equal despite a slightly higher ambient density in the single injection case as injection began $4[\mathrm{CAD}]$ later. At $\Delta t_{\mathrm{SOI}}=478[\mu \mathrm{s}]$ both fuel sprays impinge on the piston surface. The injection trigger signal had ended in the double injection experiment and fuel injection ceased resulting in a shorter duration of impingement compared to the single injection experiment in which fuel injection continued. In the single injection experiment the piston was closer to the injector at the same time after the start of injection due to the later start of injection crank angle. Martin et al. [41] found that the penetration length of the hollow cone fuel spray from an outward opening piezo injector increased linearly during injection and the penetration rate decrease significantly at the end of injection in pressure chamber measurements at $0.5[\mathrm{MPa}]$ and 1.0 $[\mathrm{MPa}]$. Based on the shorter duration of fuel spray impingement on the piston crown and the reduction of the penetration length at the cessation of injection it is conjectured that a smaller fuel mass impinged on the piston crown at $\Delta t_{\text {SOI }}=478[\mu \mathrm{s}]$ in the double injection experiment where injection had ceased compared to the single injection experiment where injection continued.

At $\Delta t_{\mathrm{SOI}}=978[\mu \mathrm{s}]$ the time from the start of the second fuel injection trigger pulse was $278[\mu \mathrm{s}]$ and the injection had lasted equally as long as the first injection at $\Delta t_{\mathrm{SOI}}=278[\mu \mathrm{s}]$. At $\Delta t_{\mathrm{SOI}}=978[\mu \mathrm{s}]$ the fuel spray penentration length was smaller and the spray was wider 
compared to the first fuel spray at $\Delta t_{\text {SOI }}=278[\mu \mathrm{s}]$. Martin et al. [41] found that the penetration length and maximum width of the hollow cone fuel spray decreased with increasing pressure. During motored conditions the single injection caused the pressure to decrease by 1 [bar] from 19 [bar] due to vaporization of the fuel. The decrease in pressure after the first injection is not thought to be sufficient to explain the increase in fuel spray width at $\Delta t_{\text {SOI }}=978[\mu \mathrm{s}]$ and the decrease in penetration length at a lower cylinder pressure is inconsistent with the pressure chamber results. An increase in the angle of the second hollow cone fuel spray using two fuel injections in an optical engine with an outward opening piezo injector was measured by [42]. A stable upward flow towards the injector in the interior of the first hollow cone fuel spray due a vortice on the inside of the leading edge of the hollow cone was identified from particle image velocimetry (PIV) measurements and was referred to as a funnel flow [42]. A correlation between the funnel flow velocity and the spray angle was found and it was concluded that the flow impinged on the second fuel spray causing the increase in spray angle. The results presented here are consistent with the PIV results in the earlier study. In the double injection experiment a greater fraction of fuel was injected during partial needle lift and a reduced injector orifice area due to the additional opening and closing of the injector caused by the additional fuel injection. Two injections of fuel results in a lower effective injector orifice area compared to a single fuel injection with the effective area decreasing with an increasing number of injections. Marchi et al. [43] found that a lower needle lift reduced the hollow cone fuel spray penetration length for both homogenous and stratified injection timings in an optical engine. A lower effective needle lift and injector orifice area is expected to result in a reduced fuel spray penetration length and a decrease in the piston crown fuel film mass based on these results.

In the experiments with two injections of fuel and ignition of the last fuel spray the ignition process was the same as for the single injection experiment. The spark occurred during the second injection of fuel and the fuel spray passing the spark plug was ignited. The flame developed in a partially premixed fuel and air mixture in the same manner as discussed for the single injection experiment. In the experiment with ignition of the first of the two fuel sprays the ignition process was also the same as shown in Figure 18. At $-11.7[\mathrm{CAD}]$ the injection of fuel was ceasing and the spark discharge occurred as the end of the fuel spray passed. The fuel spray impinged on the piston crown as in the single injection experiment and the other experiments with two injections and the same total fuel mass. A flame developed in the partially premixed fuel and air mixture as in the single injection experiment. At -6.8 [CAD] the second injection of fuel was underway and the fuel spray entered the existing flame. This resulted in a fuel rich mixture in the flame due to minimal fuel and air mixing which is conducive to the formation of soot.

Both ignition of the first fuel spray and the second in

$$
\begin{array}{cc}
n_{\mathrm{inj}}= & 1, \mathrm{SOI}=-20[\mathrm{CAD}] \\
t_{\mathrm{inj}}=560[\mu \mathrm{s}] & n_{\mathrm{inj}}=2, \mathrm{SOI}=-24[\mathrm{CAD}] \\
t_{\mathrm{inj}}=300[\mu \mathrm{s}], d_{\mathrm{inj}}=400[\mu \mathrm{s}]
\end{array}
$$

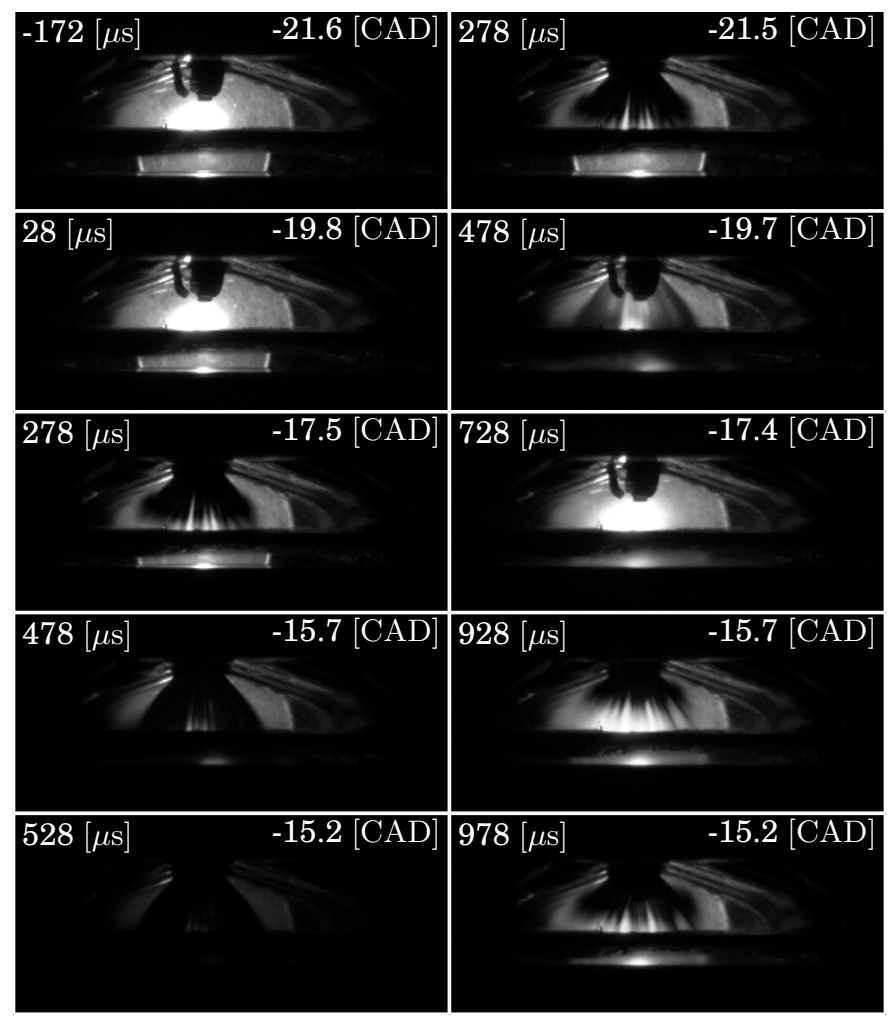

Figure 17: Comparison of the fuel injection process and the fuel sprays for a single injection and two injections with the same total fuel mass. Cycle average of cylinder liner images of fuel injection for the single injection experiment in the left column and a double injection experiment in the right column, case B and D respectively. $\omega=1500$ [RPM], $m_{\mathrm{f}}=18$ [mg]. The time relative to SOI is given in the upper left corner of each image and the crank angle is given in the upper right corner.

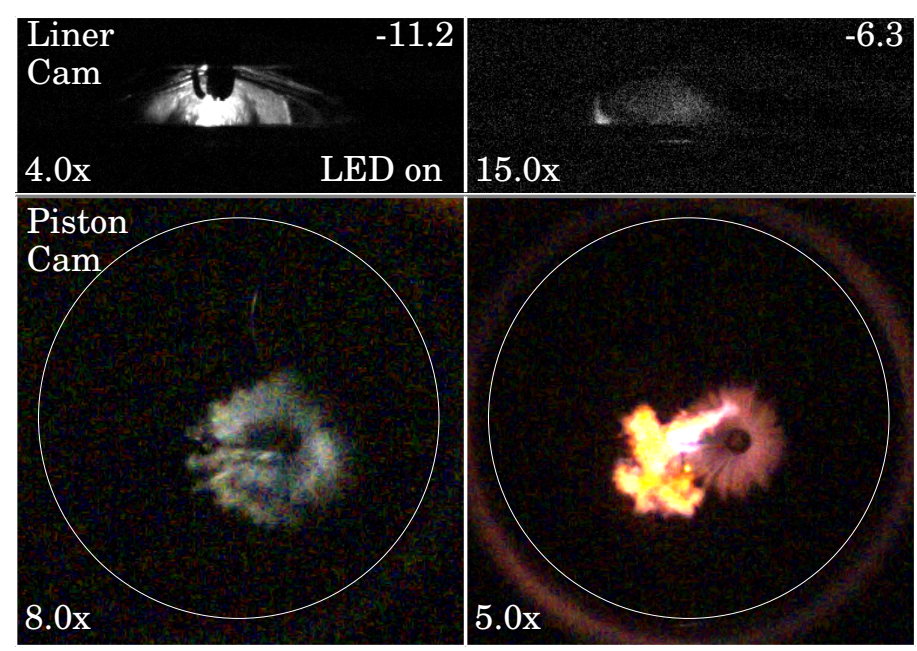

Figure 18: The ignition of the first of two fuel sprays and second injection of fuel into the developing flame. Piston crown images recorded for case $\mathrm{F}$ with ignition of the first of two fuel sprays. $\omega=$ $1500[\mathrm{RPM}], m_{\mathrm{f}}=18[\mathrm{mg}], n_{\mathrm{inj}}=2$, SOI $=16$ [CAD], SOS $=$ $12[\mathrm{CAD}]$. The images were recorded during cycle number 50 . The crank angle at which the image was recorded is given in the upper right corner. The intensity scaling is given in the lower right corner. 
the experiments using two injections resulted in a reduction in piston pool fire luminosity compared to the single injection of 18 [mg]. A comparison of the cycle average combustion luminosity at $40[\mathrm{CAD}]$ viewed through the quartz cylinder liner is shown in Figure 19. Combustion luminosity in the single injection experiment was centered on the piston crown due to diffusion flames from combustion of the liquid fuel films on the surface of the piston crown as shown in the left image in Figure 19. Combustion luminosity on the piston crown was reduced in the experiment with ignition of the second of the two fuel sprays from two injections of fuel as shown in the middle image in Figure 19. The combustion luminosity in this experiment is also attributed to pool fires on the piston crown. The reduction in the cycle average combustion luminosity suggests that the mass of the liquid fuel films on the piston crown was reduced when two injections were used to inject the same total fuel mass as in the single injection experiment. The maximum intensity of the combustion luminosity was also reduced in comparison with the single injection experiment when two injections were used and the first of the two fuel sprays was ignited which is shown in the right image in Figure 19. The total luminosity was larger when the first fuel spray was ignited in comparison to the last fuel spray. Ignition of the first fuel spray resulted in combustion luminosity which was spread over the left half of the combustion chamber volume and was not centered on the piston crown as in the two other experiments. Pool fires are not attributed as the cause of the combustion luminosity in this experiment as diffusion flames were absent on the piston crown in individual cycle average images. The absence of pool fires indicates that injecting the fixed fuel mass with two injections with a small delay resulted in a reduction of the liquid fuel film mass on the piston crown regardless of whether the first or last fuel spray was ignited. The larger total combustion luminosity resulting from early ignition indicates soot formation occurred in the gas phase rather than on the piston crown.

\section{2. $\mathrm{OH}^{*}$ Chemiluminescence and Soot Incandescence}

At ignition, $\mathrm{OH}^{*}$ chemiluminescence was measured at the spark plug electrodes in the majority of cycles with two injections for both ignition of the second and the first fuel spray as shown in Figure 20 at -14.0 [CAD] and Figure 21 at $-12.0[\mathrm{CAD}]$. The area of the $\mathrm{OH}^{*}$ chemiluminescence was equal in both experiments to the single injection experiment. The $\mathrm{OH}^{*}$ chemiluminescence results at ignition are the same as for the single injection experiment shown in Figure 15 indicating that the ignition mechanism was the same in all three experiments and was independent of the individual injection durations used in the experiments. For both experiments the area and total $\mathrm{OH}^{*}$ chemiluminescence shown in Figure 23 and Figure 24 initially increased in the absence of soot incandescence in the same manner as in the single injection case suggesting that the flame also propagated into near stoichiometric regions of the partially mixed fuel and air mixture given the requirement of fuel rich conditions for the formation of soot. The total soot incandescence in the experiment with ignition of the last of the two fuel sprays in Figure 24 was significantly smaller throughout the combustion process in comparison to the total soot incandescence for the single injection experiment in Figure 16. The total soot incandescence measured disappeared at approximately the same crank angle as the $\mathrm{OH}^{*}$ chemiluminescence. The low amount of soot formation occurred entirely while conditions were conducive to the oxidation of any soot formed. The low level of soot formation occurred in pool fires with low cycle frequencies as shown in Figure 20. The absence of soot incandescence with an intensity greater than the threshold outside of the pool fires in all cycles indicates that fuel rich partially premixed combustion did not occur. It is conjectured that the longer time from the start of the first injection to ignition and combustion in comparison with the single injection experiment and the increased turbulence prior to the second injection caused by the first fuel spray resulted in a greater mixing of fuel and air and a lower maximum local fuel stoichiometry.

The total soot incandescence was significantly greater for the experiment with ignition of the first of two fuel sprays compared to both ignition of the second fuel spray and the single injection experiment as shown in Figure 21 while the total $\mathrm{OH}^{*}$ chemiluminescence for case $\mathrm{D}$ and $\mathrm{F}$ was equal in both magnitude and development. From both individual cycle images and the average cycle image at 40 [CAD] shown in Figure 19 for this experiment the soot incandescence measured after ignition of the first fuel spray in Figure 21 occurred primarily due to fuel rich combustion in the gas phase rather than due to pool fires. The soot incandescence persisted until after the end of conditions favorable to soot oxidation in the same manner as observed for piston crown pool fires. The soot incandescence was measured over a large fraction of the combustion chamber consistent with the combustion luminosity in Figure 19.

The total $\mathrm{OH}^{*}$ chemiluminescence and soot incandescence in the experiment with four injections of 26 [mg] and ignition of the last fuel spray in Figure 25 followed the same trends observed for case D with two injections of 18 [mg] of fuel indicating the same flame propagation behaviour. The maximum total $\mathrm{OH}^{*}$ chemiluminescence and soot incandescence increased compared to case D with the peak values occurring at the same crank angles as for case D for each source respectively.

In particular, the spatial distribution of $\mathrm{OH}^{*}$ chemiluminescence and soot incandescence in Figure 22 was remarkably similar to the spatial distribution observed in Figure 20 for the experiment case D with two injections of 18 [mg]. A void in the $\mathrm{OH}^{*}$ chemiluminescence similar to the voids observed in Figure 20 and 21 for the both of the two injection experiments respectively is also present with a reduced extent. The cycle frequency is greater for the observed spatial distribution of both $\mathrm{OH}^{*}$ chemiluminescence and soot incandescence. These observations suggest 


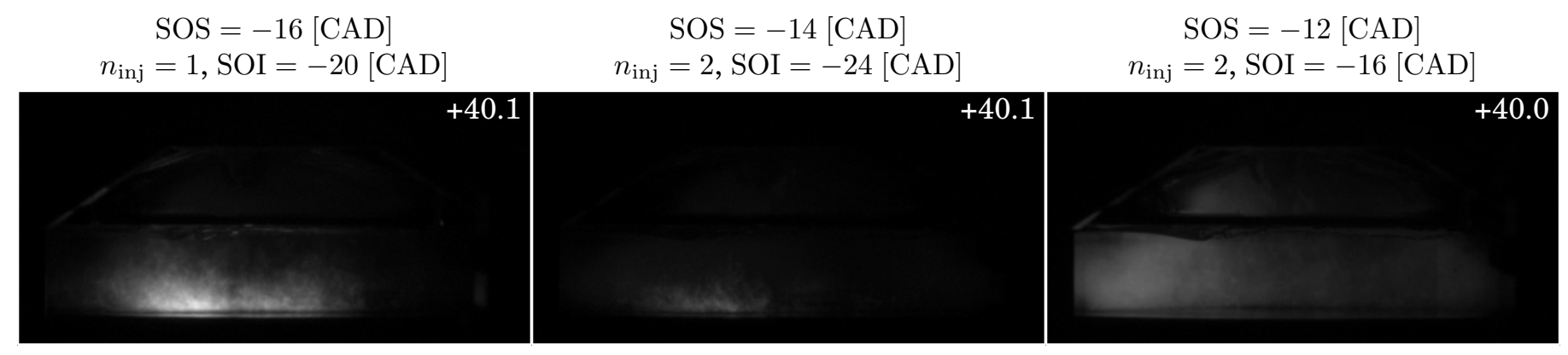

Figure 19: Comparison of the visible luminosity location and intensity towards the end of the combustion process for the experiments with a single injection and two injections. Cycle average of cylinder liner images recorded for the experiment with a single fuel injection and for the experiments with two injections of fuel and ignition of the second and first fuel sprays respectively with $\omega=1500[\mathrm{RPM}], m_{\mathrm{f}}=18[\mathrm{mg}]$.

that the additional injections and fuel mass had a minimal effect on the fuel and air mixture formation and the flame propagation when multiple injections in close succession were used. The same mechanism resulting in a $\mathrm{OH}^{*}$ chemiluminescence void also appears to have been present when the number of injections was increased from two to four. The primary source of soot formation was from pool fires. Soot incandescence with a low cycle frequency was measured at the spark plug electrodes with the same duration as the soot incandescence from the piston crown pool fires. The spark plug soot incandescence indicates diffusion flames from combustion of liquid fuel films on the spark plug electrodes deposited by fuel spray impingement.

\section{Conclusion}

Globally lean spray guided stratified combustion of E85 and the sources of soot formation were studied in a single cylinder engine with optical access using a piezo actuated outward opening pintle fuel injector. The cycle fuel quantity (engine load), rotational frequency and injection strategy were varied to determine the effect of these parameters on combustion and the formation and oxidation of soot. Single and multiple fuel injections per cycle were investigated. Temporally and spatially resolved optical measurements of fuel injection, ignition and combustion were recorded. The flame propagation, soot formation and soot oxidation was studied using $\mathrm{OH}^{*}$ chemiluminescence and soot incandescence.

Stable ignition of the fuel spray was not possible for the single injection of the larger of the two cycle fuel quantities indicating that a critical maximum injection duration existed for stable fuel spray ignition. Dividing the single injection of the larger cycle fuel quantity into multiple injections allowed stable ignition of the fuel spray.

The rate of combustion and IMEP increased and the IMEP variation decreased when multiple injections of fuel with a small delay between injections were used. When the cycle fuel mass was increased, multiple injections had the same effect and significantly increased the maximum rate of heat release, IMEP and combustion stability in comparison with a single injection of the fuel mass.

After ignition the developing flame propagated in partially mixed fuel and air resulting from the limited mixing of fuel and air that occurred during and after the injection of fuel and prior to the end of combustion. Initial flame propagation occurred in the absence of soot incandescence. Given that fuel rich conditions are required for the formation of soot it is likely that early flame propagation occurred in stoichiometric to fuel lean regions of the partially mixed fuel and air. Regions of the combustion chamber were devoid of fuel and combustion indicating an inhomogeneous fuel and air mixture. A single injection of fuel led to the fuel spray impinging on the piston crown. This resulted in liquid fuel films on the piston crown and pool fires consisting of diffusion flames which persisted through the expansion stroke.

The fuel spray penentration length and total fuel impingement duration was reduced when multiple injections were used to inject the same total cycle fuel mass due. This was due to the shorter duration of each individual injection and a smaller effective injector orifice area over the course of the injection. An upward funnel flow, established in the center of the first fuel spray, impinged on the injector and increased the angle of the nexy fuel spray. Replacing a single fuel injection with multiple injections reduced the magnitude of the piston crown pool fires to the extent that pool fires were nearly eliminated in comparison with the pool fires resulting from a single injection of fuel. Ignition of the first of two fuel sprays caused the second fuel spray to enter the developing flame resulting in fuel rich combustion and conditions conducive to the formation of soot.

The $\mathrm{OH}^{*}$ chemiluminescence was detected at the spark plug in every cycle from ignition of the fuel spray indicating repeatable ignition of the fuel spray. Soot incandescence was absent during the initial increase in the extent of the $\mathrm{OH}^{*}$ chemiluminescence after ignition. Initial flame propagation is conjectured to have occurred in near stoichiometric regions of the partially mixed fuel and air based on these observations. Voids in the $\mathrm{OH}^{*}$ chemilumines- 


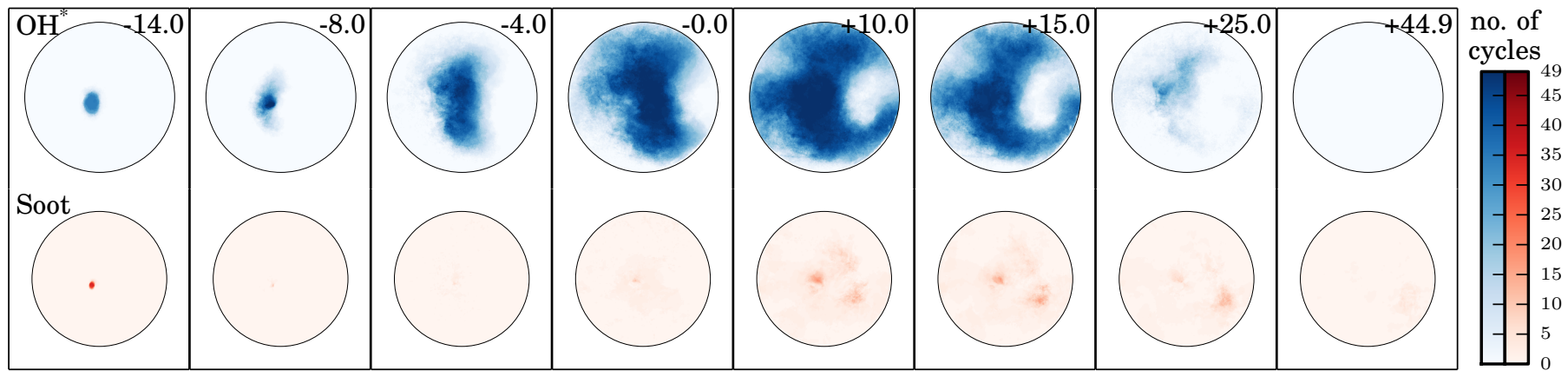

Figure 20: The spatial distribution and frequency of $\mathrm{OH}^{*}$ chemiluminescence and soot incandescence for case $\mathrm{D}\left(\omega=1500[\mathrm{RPM}], m_{\mathrm{f}}=\right.$ $18[\mathrm{mg}]$, two injections, SOI $=-24[\mathrm{CAD}], d_{\mathrm{inj}}=400 \cdot 10^{-6}[\mathrm{~s}]$ and $\left.\mathrm{SOS}=-14[\mathrm{CAD}]\right)$. Sum of thresholded $\mathrm{OH}^{*}$ and soot incandescence images recorded for 49 cycles. The crank angle at which the images were recorded is denoted in the top right corner of each pair of images. The black circles mark the edge of the piston crown window. The images have been clipped to the area inside the piston crown window.

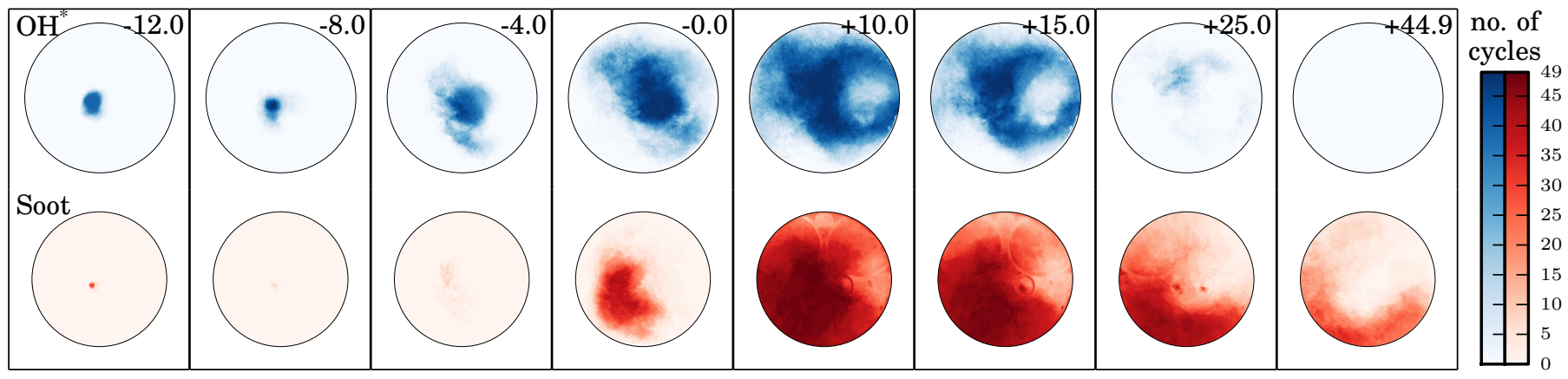

Figure 21: The spatial distribution and frequency of $\mathrm{OH}^{*}$ chemiluminescence and soot incandescence for case $\mathrm{F}\left(\omega=1500[\mathrm{RPM}], m_{\mathrm{f}}=\right.$ $18[\mathrm{mg}]$, two injections, SOI $=-16[\mathrm{CAD}], d_{\mathrm{inj}}=400 \cdot 10^{-6}[\mathrm{~s}]$ and $\left.\mathrm{SOS}=-12[\mathrm{CAD}]\right)$. Sum of thresholded OH* and soot incandescence images recorded for 49 cycles. The crank angle at which the images were recorded is denoted in the top right corner of each pair of images. The black circles mark the edge of the piston crown window. The images have been clipped to the area inside the piston crown window.

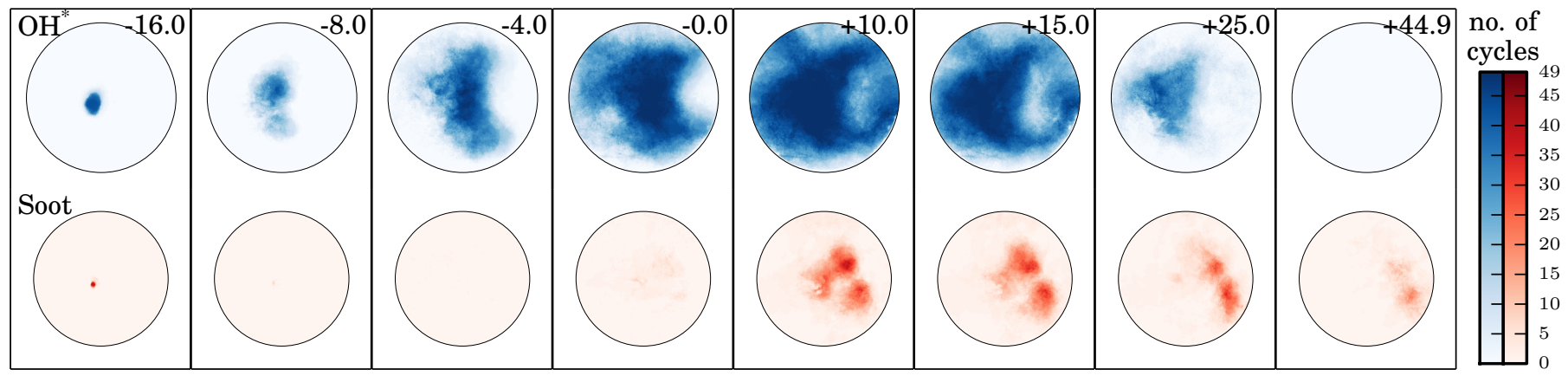

Figure 22: The spatial distribution and frequency of $\mathrm{OH}^{*}$ chemiluminescence and soot incandescence for case $\mathrm{H}\left(\omega=1500[\mathrm{RPM}], m_{\mathrm{f}}=\right.$ $26[\mathrm{mg}]$, four injections, SOI $=-30[\mathrm{CAD}], d_{\mathrm{inj}}=220 \cdot 10^{-6}[\mathrm{~s}]$ and $\left.\mathrm{SOS}=-16[\mathrm{CAD}]\right)$. Sum of thresholded OH* and soot incandescence images recorded for 49 cycles. The crank angle at which the images were recorded is denoted in the top right corner of each pair of images. The black circles mark the edge of the piston crown window. The images have been clipped to the area inside the piston crown window. 


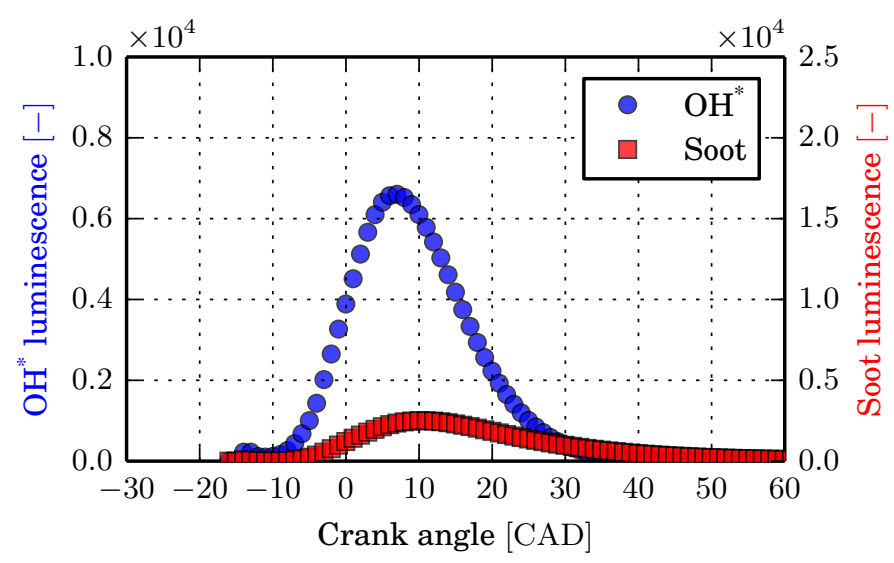

Figure 23: Total $\mathrm{OH}^{*}$ chemiluminescence and soot incandescence intensity during combustion for case D $\left(\omega=1500[\mathrm{RPM}], m_{\mathrm{f}}=\right.$ $18[\mathrm{mg}]$, two injections, SOI $=-24[\mathrm{CAD}], d_{\mathrm{inj}}=400[\mu \mathrm{s}]$ and $\mathrm{SOS}=-14[\mathrm{CAD}])$. Cycle average of the spatially summed intensity of 49 cycles as a function of crank angle recorded.

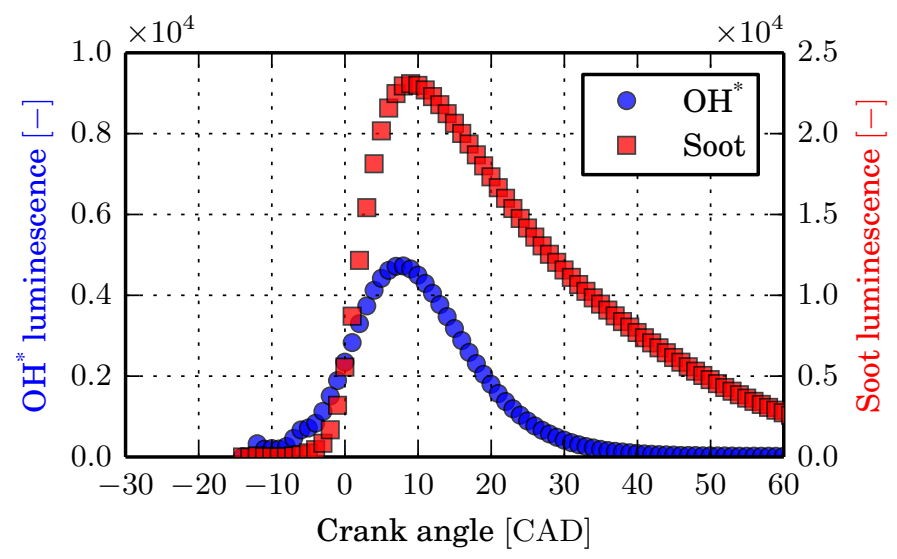

Figure 24: Total $\mathrm{OH}^{*}$ chemiluminescence and soot incandescence intensity during combustion for case $\mathrm{F}\left(\omega=1500[\mathrm{RPM}], m_{\mathrm{f}}=\right.$ $18[\mathrm{mg}]$, two injections, SOI $=-16[\mathrm{CAD}], d_{\mathrm{inj}}=400[\mu \mathrm{s}]$ and $\mathrm{SOS}=-12[\mathrm{CAD}])$. Cycle average of the spatially summed intensity of 49 cycles as a function of crank angle recorded.

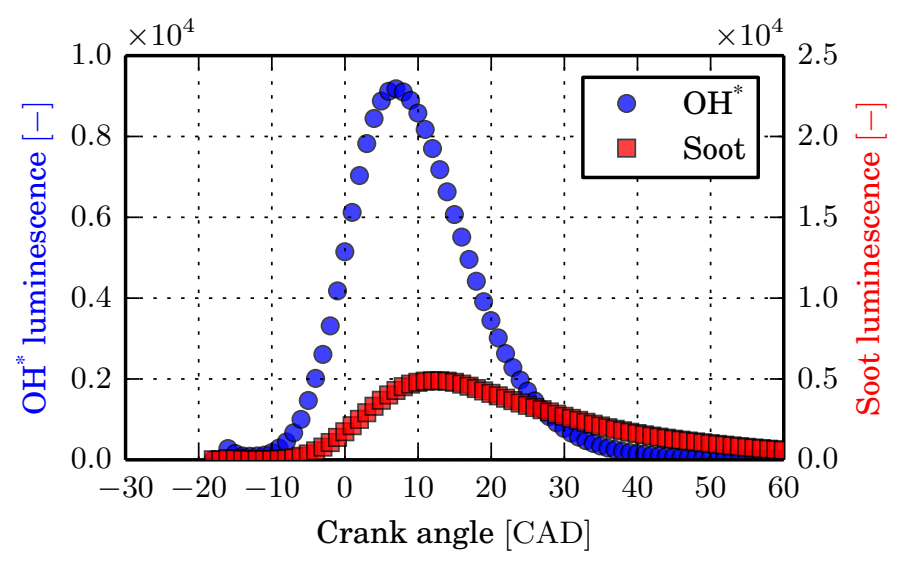

Figure 25: Total $\mathrm{OH}^{*}$ chemiluminescence and soot incandescence intensity during combustion for case $\mathrm{H}\left(\omega=1500[\mathrm{RPM}], m_{\mathrm{f}}=\right.$ $26[\mathrm{mg}]$, four injections, SOI $=-30[\mathrm{CAD}], d_{\mathrm{inj}}=220[\mu \mathrm{s}]$ and $\mathrm{SOS}=-16[\mathrm{CAD}])$. Cycle average of the spatially summed intensity of 49 cycles as a function of crank angle recorded. cence occurred during the early flame propagation due to fuel lean regions which disappeared as the flame subsequently propagated into the regions.

Soot incandescence increased as the flame continued to propagate into fuel rich regions resulting in soot formation in the gas phase. Conditions conducive to the oxidation of soot were present during the early soot formation. The soot incandescence from fuel rich partially premixed combustion in the gas phase ceased during favourable soot oxidation conditions when the last fuel spray was ignited. In the single injection experiment soot formation from liquid fuel film diffusion flames on the piston increased as the enflamed volume peaked gas phase soot formation decreased. The soot formation from pool fires persisted after the end of favourable soot oxidation conditions. Piston pool fires were the primary source of soot formation when a single injection was used.

Multiple injections and ignition of the last fuel spray greatly reduced soot incandescence from pool fires for both engine loads. Ignition of the last of two fuel sprays in the lower load experiment effectively eliminated soot incandescence from partially premixed combustion in the gas phase. Ignition of the first of two fuel sprays resulted in soot formation from fuel rich combustion in the gas phase which persisted until after the end of favourable soot oxidation conditions. The spatial distribution and cycle frequency of the $\mathrm{OH}^{*}$ chemiluminescence and soot incandescence for two injections in the low load case and four injections in the medium load case were remarkably similar suggesting the additional injections and fuel mass had a minimal impact on mixture formation and flame propagation when multiple injections were used in close succession.

\section{Acknowledgements}

The authors wish to thank the Swedish Energy Agency for financial support, Volvo Car Corporation for in-kind support and Research Engineer Eugenio de Benito Sienes, Associate Professor Mats Andersson, Associate Professor Petter Dahlander, Assistant Professor David Sedarsky and Professor Ingemar Denbratt for their contributions to the work presented herein.

\section{References}

[1] Richard van Basshuysen, editor. Gasoline Engine with Direct Injection. Vieweg+Teubner, 1st edition, 2009.

[2] John Heywood. Internal Combustion Engine Fundamentals. McGraw-Hill Higher Education, 1989. ISBN 978-0071004992.

[3] F. Zhao, M. C. Lai, and D. L. Harrington. Automotive sparkignited direct-injection gasoline engines. Progress in Energy and Combustion Science, 25:437-562, 1999. doi:10.1016/S03601285(99)00004-0.

[4] Alex C. Alkidas. Combustion advancements in gasoline engines. Energy Conversion and Management, 48:2751-2761, 2007. doi:10.1016/j.enconman.2007.07.027.

[5] B. R. Stanmore. The oxidation of soot: a review of experiments, mechanisms and models. Carbon, 39:2247-2268, 2001. doi:10.1016/S0008-6223(01)00109-9. 
[6] Henning Bockhorn, editor. Soot Formation in Combustion, volume 59 of Springer Series in Chemical Physics. Springer, 1st edition, 1994. doi:10.1007/978-3-642-85167-4.

[7] Boris D. Stojkovic, Todd D. Fansler, Michael C. Drake, and Volker Sick. High-speed imaging of $\mathrm{OH}^{*}$ and soot temperature and concentration in a stratified-charge direct-injection gasoline engine. Proceedings of the Combustion Institute, 30(2):26572665, 2005. doi:10.1016/j.proci.2004.08.021.

[8] Heechang Oh and Choongsik Bae. Effects of the injection timing on spray and combustion characteristics in a spray-guided DISI engine under lean-stratified operation. Fuel, 107:225-235, 2013. doi:10.1016/j.fuel.2013.01.019.

[9] Magnus Sjöberg and David Reuss. High-speed imaging of sprayguided DISI engine combustion with near-TDC injection of E85 for ultra-low NO and soot. Proceedings of the Combustion Institute, 34(2):2933-2940, 2013. doi:10.1016/j.proci.2012.05.033.

[10] M. C. Drake, T. D. Fansler, A. S. Solomon, and G. A. Szekely. Piston Fuel Films as a Source of Smoke and Hydrocarbon Emissions from a Wall-Controlled Spark-Ignited DirectInjection Engine. SAE Technical Paper 2003-01-0547, 2003. doi:10.4271/2003-01-0547.

[11] Eric Stevens and Richard Steeper. Piston Wetting in an Optical DISI Engine: Fuel Films, Pool Fires, and Soot Generation. SAE Technical Paper 2001-01-1203, 2001. doi:10.4271/200101-1203.

[12] Amin Velji, Kitae Yeom, Uwe Wagner, Ulrich Spicher, Martin Roßbach, Rainer Suntz, and Henning Bockhorn. Investigations of the Formation and Oxidation of Soot Inside a Direct Injection Spark Ignition Engine Using Advanced Laser-Techniques. SAE Technical Paper 2010-01-0352, 2010. doi:10.4271/201001-0352.

[13] Stina Hemdal, Mats Andersson, Petter Dahlander, Raul Ochoterena, and Ingemar Denbratt. In-cylinder soot imaging and emissions of stratified combustion in a sparkignited spray-guided direct-injection gasoline engine. International Journal of Engine Research, 12:549-563, 2011. doi: $10.1177 / 1468087411418167$.

[14] Poonam Singh Nigam and Anoop Singh. Production of liquid biofuels from renewable resources. Progress in Energy and Combustion Science, 37:52-68, 2011. doi:10.1016/j.pecs.2010.01.003.

[15] Avinash Kumar Agarwal. Biofuels (alcohols and biodiesel) applications as fuels for internal combustion engines. Progress in Energy and Combustion Science, 33:233-271, 2007. doi:10.1016/j.pecs.2006.08.003.

[16] Tien Mun Foong, Kai J. Morganti, Michael J. Brear, Gabriel da Silva, Yi Yang, and Frederick L. Dryer. The octane numbers of ethanol blended with gasoline and its surrogates. Fuel, 115: 727-739, 2014. doi:10.1016/j.fuel.2013.07.105.

[17] L. Zigan, I. Schmitz, A. Flügel, M. Wensing, and A. Leipertz. Structure of evaporating single- and multicomponent fuel sprays for 2nd generation gasoline direct injection. Fuel, 90:348-363, 2011. doi:10.1016/j.fuel.2010.08.001.

[18] P. G. Aleiferis, J. Serras-Pereira, Z. van Romunde, J. Caine, and M. Wirth. Mechanisms of spray formation and combustion from a multi-hole injector with e85 and gasoline. Combustion and Flame, 157:735-756, 2010. doi:10.1016/j.combustflame.2009.12.019.

[19] G. Broustail, F. Halter, P. Seers, G. Moréac, and C. MounaïmRousselle. Experimental determination of laminar burning velocity for butanol/iso-octane and ethanol/iso-octane blends for different initial pressures. Fuel, 106:310-317, 2013. doi:10.1016/j.fuel.2012.10.066.

[20] P. Dirrenberger, P. A. Glaude, R. Bounaceur, H. Le Gall, A. Pires da Cruz, A. A. Konnov, and F. Battin-Leclerc. Laminar burning velocity of gasolines with addition of ethanol. Fuel, 115:162-169, 2014. doi:10.1016/j.fuel.2013.07.015.

[21] Heechang Oh, Choongsik Bae, and Kyoungdoug Min. Spray and Combustion Characteristics of Ethanol Blended Gasoline in a Spray Guided DISI Engine under Lean Stratified Operation. SAE International Journal of Engines, 3(2):213-222, 2010. doi:10.4271/2010-01-2152.
[22] Loic de Francqueville. Effects of Ethanol Addition in RON 95 Gasoline on GDI Stratified Combustion. SAE Technical Paper 2011-24-0055, 2011. doi:10.4271/2011-24-0055.

[23] Magnus Sjöberg and David Reuss. NOx-Reduction by InjectionTiming Retard in a Stratified-Charge DISI Engine using Gasoline and E85. SAE Internation Journal of Fuels and Lubricants, 5(3), 2012. doi:10.4271/2012-01-1643.

[24] H. Zhao and N. Ladommatos. Optical diagnostics for soot and temperature measurement in diesel engines. Progress in Energy and Combustion Science, 24(3):221-255, 1998. doi:10.1016/S0360-1285(97)00033-6.

[25] Charles P. Fenimore and George Wallace Jones. Oxidation of soot by hydroxyl radicals. Journal of Physical Chemistry, 71 (3):593-597, 1967. doi:10.1021/j100862a021.

[26] Kazuhiro Hayashida, Shogo Nagaoko, and Hiromi Ishitani. Growth and oxidation of graphitic crystallites in soot particles within a laminar diffusion flame. Fuel, 128:148-154, 2014. doi:10.1016/j.fuel.2014.03.008.

[27] A. Cavaliere, R. Barbella, A. Ciajolo, A. D'Anna, and R. Ragucci. Fuel and Soot Oxidation in Diesel-Like Conditions. Symposium (International) on Combustion, 25(1):167174, 1994. doi:10.1016/S0082-0784(06)80641-7.

[28] Irvin Glassman and Richard Yetter. Combustion. Academic Press, 4th edition, 2008. ISBN 978-0-12-088573-2.

[29] N. Leplat, P. Dagaut, C. Togbé, and J. Vandooren. Numerical and experimental study of ethanol combustion and oxidation in laminar premixed flames and in jetstirred reactor. Combustion and Flame, 158:705-725, 2011. doi:10.1016/j.combustflame.2010.12.008.

[30] Philippe Dagaut and Casimir Togbé. Experimental and Modeling Study of the Kinetics of Oxidation of Ethanol-Gasoline Surrogate Mixtures (E85 Surrogate) in a Jet-Stirred Reactor. Energy \& Fuels, 22:3499-3505, 2008. doi:10.1021/ef800214a.

[31] A. G. Gaydon. The Spectroscopy of Flames. Springer, 2nd edition, 1974. ISBN 978-94-009-5722-0. doi:10.1007/978-94009-5720-6.

[32] G. H. Dieke and H. M. Crosswhite. The ultraviolet bands of $\mathrm{OH}$ Fundamental data. Journal of Quantitative Spectroscopy and Radiative Transfer, 2(2):97-199, 1962. doi:10.1016/00224073(62)90061-4.

[33] R. P. Porter, A. H. Clark, W. E. Kaskan, and W. E. Browne. A study of hydrocarbon flames. Symposium (International) on Combustion, 11(1):907-917, 1967. doi:10.1016/S00820784(67)80217-0.

[34] S. A. Carl, M. Van Poppel, and J. Peeters. Identification of the $\mathrm{CH}+\mathrm{O}_{2} \longrightarrow \mathrm{OH}(\mathrm{A})+\mathrm{CO}$ Reaction as the Source of $\mathrm{OH}(\mathrm{A}-\mathrm{X})$ Chemiluminescence in $\mathrm{C}_{2} \mathrm{H}_{2} / \mathrm{O} / \mathrm{H} / \mathrm{O}_{2}$ Atomic Flames and Determination of Its Absolute Rate Constant over the Range $\mathrm{T}$ $=296$ to $511 \mathrm{~K}$. Journal of Physical Chemistry A, 107(50): 11001-11007, 2003. doi:10.1021/jp035568j.

[35] David S. Dandy and Steven R. Vosen. Numerical and Experimental Studies of Hydroxyl Radical Chemiluminescence in Methane-Air Flames. Combustion Science and Technology, 82: 131-150, 1992. doi:10.1080/00102209208951816.

[36] Heechang Oh, Choongsik Bae, Jungseo Park, and Jeeyeon Jeon. Effect of Multiple Injection on Stratified Combustion Characteristics in a Spray-Guided DISI Engine under Lean Stratified Operation. SAE Technical Paper 2011-24-0059, 2011. doi:10.4271/2011-24-0059.

[37] Fred W. Bowditch. A New Tool for Combustion Research A Quartz Piston Engine. SAE Technical Paper 610002, 1961. doi: $10.4271 / 610002$.

[38] Per Tunestål. Self-tuning gross heat release computation for internal combustion engines. Control Engineering Practice, 17: 518-524, 2009. doi:10.1016/j.conengprac.2008.09.012.

[39] Paolo Sementa, Bianca Maria Vaglieco, and Francesco Catapano. Thermodynamic and optical characterizations of a high performance GDI engine operating in homogeneous and stratified charge mixture conditions fueled with gasoline and bioethanol. Fuel, 96:204-219, 2012. doi:10.1016/j.fuel.2011.12.068.

[40] Michael F. Modest. Radiative Heat Transfer. Academic Press, 
3rd edition edition, 2013. ISBN 978-0-12-386944-9.

[41] D. Martin, P. Pischke, and R. Kneer. Investigation of the influence of multiple gasoline direct injections on macroscopic spray quantities at different boundary conditions by means of visualization techniques. International Journal of Engine Research, 11(6):439-454, 2010. doi:10.1243/14680874JER525.

[42] R. Stiehl, J. Schorr, C. Krüger, A. Dreizler, and B. Böhm. In-Cylinder Flow and Fuel Spray Interactions in a Stratified Spray-Guided Gasoline Engine Investigated by High-Speed Laser Imaging Techniques. Flow Turbulence Combustion, 91: 431-450, 2013. doi:10.1007/s10494-013-9500-x.

[43] A. Marchi, J. Nouri, Y. Yan, and C. Arcoumanis. Spray stability of outwards opening pintle injectors for stratified direct injection spark ignition engine operation. International Journal of Engine Research, 11(6):413-437, 2010. doi:10.1243/14680874JER605. 